\title{
Analyzing the feasibility of a space-borne sensor (SPOT-6) to estimate the height of submerged aquatic vegetation (SAV) in inland waters
} \author{
Enner H. Alcântara ${ }^{\mathrm{c}}$, Nilton N. Imai ${ }^{\mathrm{a}}$

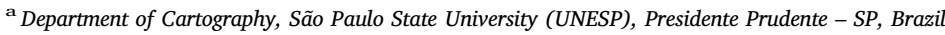 \\ ${ }^{\mathrm{b}}$ Center for Geospatial Research, Department of Geography, University of Georgia (UGA), Athens, GA, USA \\ ${ }^{\mathrm{c}}$ Department of Environment Engineering, São Paulo State University (UNESP), São José dos Campos - SP, Brazil
}

Luiz Henrique S. Rotta ${ }^{a}$, Deepak R. Mishra ${ }^{b, *}$, Fernanda S.Y. Watanabe ${ }^{a}$, Thanan W.P Rodrigues ${ }^{a}$,

\section{A R T I C L E I N F O}

\section{Keywords:}

Radiative transfer models

Reflectance

Attenuation

Water column correction

Bottom albedo

Hydroacoustic data

Invasive species

Reservoir management

\begin{abstract}
A B S T R A C T
Remote sensing based approaches have been widely used over the years to monitor and manage submerged aquatic vegetation (SAV) or aquatic macrophytes mainly by mapping their spatial distribution and at the most, modeling SAV biomass. Remote sensing based studies to map SAV heights are rare because of the complexities in modeling water column optical proprieties. SAV height is a proxy for biomass and can be used to estimate plant volume when combined with percent cover. The objective of this study was to explore the feasibility of a satellite sensor to estimate the SAV height distribution in an inland reservoir. Also to test different radiative transfer theory based bio-optical models for estimating SAV heights using SPOT-6 data. The satellite-based multispectral data have rarely been used and SPOT- 6 data, to the best of our knowledge, have never been used to estimate SAV heights in inland water bodies. In addition to depth and hydroacoustic data, in situ hyperspectral radiance and irradiance were measured at different depths to compute remote sensing reflectance $\left(R_{r s}\right)$ and the attenuation coefficients $\left(K_{d}\right.$ and $\left.K_{L u}\right)$. Two models, Palandro et al. (2008) and Dierssen et al. (2003), were used to derive bottom reflectance from both in situ and atmospherically corrected SPOT-6 $R_{r s}$. Bottom reflectance-based vegetation indices (green-red index, slope index, and simple ratio) were used to estimate SAV heights. Validation was performed using echosounder acquired hydroacoustic data. In situ model calibration produced an $\mathrm{R}^{2}$ of 0.7 , however, the validation showed a systematic underestimation of SAV heights and high Root Mean Square Error (RMSE); indicating that there is a greater sensitivity in in situ models to localized variations in water column optical properties. The model based on SPOT- 6 data presented higher accuracy, with $\mathrm{R}^{2}$ of 0.54 and RMSE of $0.29 \mathrm{~m}$ (NRMSE $=15 \%$ ). Although the models showed a decreased sensitivity for SAVs at depths greater than $5 \mathrm{~m}$ with a height of $1.5 \mathrm{~m}$, the finding nonetheless is significant because it proves that re-calibration of existing bottom reflectance models with more field data can enhance the accuracy to be able to periodically map SAV heights and biomass in inland waters. Although the initial results presented in this study are encouraging, further calibration of the model is required across different species, seasons, sites, and turbidity regime in order to test its application potential.
\end{abstract}

\section{Introduction}

Excessive growth of submerged aquatic vegetation (SAV) or submerged macrophytes in inland waters can produce negative economic and ecologic impacts. But when managed properly they play several important functions, such as influencing nutrient cycling, maintaining water and sediment chemistry, providing food and shelter for various invertebrates and vertebrates, and changing the spatial structure of the waterscape by increasing habitat complexity (Thomaz et al., 2008). In addition to spreading rapidly around the globe by anthropogenic means such as dispersal via hitchhiking and unauthorized release, some of the invasive SAV species have experienced a range-shift in past few decades spreading to higher latitudes mainly due to a pattern shift in temperature, precipitation, and atmospheric $\mathrm{CO}_{2}$ triggered by climate change. Inland waters with ecological imbalance can facilitate an uncontrolled growth of SAV, which could be a significant problem especially in developing countries with lax regulations such as Brazilian reservoirs. Negative economic and ecologic impacts caused by excessive SAV will affect navigation, water quality and supply, hydropower, irrigation, fisheries, recreation, human and animal health, and land

\footnotetext{
* Corresponding author at: Department of Geography, University of Georgia, 210 Field Street, Room 204, Athens, GA 30602, USA.

E-mail address: dmishra@uga.edu (D.R. Mishra).
} 
values (Jakubauskas et al., 2002; Rockwell, 2003). SAV will have major effects on the productivity and biogeochemical cycles of the system (Carpenter \& Lodge, 1986). The increased run-off to the water body in the rainy season may cause fragmentation of SAV, obstructing water passing though the turbines of the hydroelectric plants causing significant economic damage (Marcondes et al., 2003). According to Wetzel (2001), excessive growth of macrophytes can curtail or eliminate human use of reservoirs, lakes and river ecosystems; hence several approaches (i.e., mechanical, biological, chemical) have been proposed for the control and management of aquatic macrophytes. Mechanical control primarily involves cutting and removal of the vegetation (Engel, 1990; Armellina et al., 1996; Velini, 2005). Biodegradable or biologically inactive herbicides are commonly used as chemical control (Schmidt, 2009). Sterile Grass Carp are widely used as biological control because of their aggressive grazing (Chilton and Muoneke, 1992; Hanlon et al., 2000; Wells et al., 2003). However, the type and magnitude of the control is mainly dependent on the spatial distribution of SAV extent and biomass (Wetzel, 2001).

Remote sensing technologies have the potential to map and quantify the SAV distribution and biomass at frequent interval. In fact, studies using remote sensing-based empirical and radiative transfer models to identify and map SAVs and other benthic habitats are fairly common in estuarine and coastal environments compared to inland freshwater environments (Dekker et al., 2005; Mishra et al., 2007; Hunter et al., 2010; Roelfsema et al., 2014). Remote sensing techniques have been rarely used to map SAV heights in optically complex inland waters. SAV height, a proxy for biomass, is an important biophysical property and can be used to estimate underwater light availability and plant volume when combined with percent cover. In addition, per-pixel SAV height data is easier to collect in the field compared to biomass which is often the limiting factor in robust calibration of remote sensing models.

Mapping SAV in freshwaters using satellite remote sensing can overcome problems related to access, scale, and distribution; however, high-resolution images are required with appropriate spectral characteristics (Ashraf et al., 2010). However, remote sensing data used in SAV mapping, with a few exceptions, tend to be either in situ or airborne multi- or hyperspectral data not satellite data. For example, Mishra et al. (2007) used hyperspectral Airborne Imaging Spectroradiometer for Applications (AISA) Eagle data to detect and classify the seagrasses, coral reef and associated benthic habitats. The importance of removing the effect of the water column in order to achieve accurate mapping of benthic habitats was emphasized in the study. Roelfsema et al. (2014) presented a semi-automated object-based image analysis approach for mapping dominant seagrass species, percentage cover and above-ground biomass of a shallow, clear water seagrass habitat using a time-series of field data and coincident high spatial resolution satellite imagery for the Eastern Banks, Moreton Bay, Australia. Hunter et al. (2010) used data from Compact Airborne Spectrographic Imager-2 (CASI-2) to map the distribution of macrophytes in shallow lakes $(<2.5 \mathrm{~m}$ mean depth) in the Upper Thurne region of the Norfolk Broads, UK. Giardino et al. (2015) presented an application of a physics-based method that relies on spectral inversion procedures to estimate benthic substrate types in Lake Trasimeno (Italy) from airborne imaging spectrometry data. Pande-Chhetri et al. (2014) presented methods to classify SAVs in shallow water $(<3 \mathrm{~m})$ using the airborne CASI hyperspectral sensor in St. Johns River, Florida (USA). Zou et al. (2013) studied the spectral characteristics of SAV using in situ data in a eutrophic aquatic system (Shanghai, China). They observed a nonproportional decrease in reflectance with the reduction of SAV coverage. Visser et al. (2015) investigated the possibility of creating maps of SAV depth distribution in shallow clear water streams using lowaltitude optical remote sensing. At the time of sampling, their study sites had a maximum water depth of around $0.5 \mathrm{~m}$ and low turbidity. Similarly, Williams et al. (2003) studied the use of high spatial resolution hyperspectral remote sensing to map SAV distributions and abundance in the Potomac River, Maryland, USA.
In terms of satellite-based studies, Dekker et al. (2005) used Landsat images to detect the change in seagrass and macrophyte communities of Wallis Lake, a shallow estuarine lake in New South Wales, Australia over a period of 14 years. Dogan et al. (2009) used QuickBird satellite image to identify and map SAV, with high accuracy, in a shallow lake (i.e., mean and maximum depths were 2.1 and $3.5 \mathrm{~m}$, respectively). Heblinski et al. (2011) monitored and assessed the status of littoral vegetation in Lake Sevan (Armenia), with a depth up to $\sim 3 \mathrm{~m}$ using QuickBird data. These studies concluded that accurate mapping of SAV species relies on the condition of the water column being sufficiently transparent to obtain a significant discriminatory part of the spectrum of the substrate. Epiphytic growth over SAV could also be a confounding factor and hyperspectral remote sensing could resolve this issue more clearly, however, there would be a significant increase in the cost of data acquisition.

Several other studies have concluded that high resolution airborne or satellite images may not be able to extract information about SAV in relatively deep reservoirs using frequently adopted simple methods such as image classification or empirical band ratios because of the target's low signal to noise ratio (Rotta et al., 2016, 2013; Boschi, 2011; Malthus, 2017). Semi-analytical models have been proposed as an alternative to remove the water column influence and to retrieve bottom reflectance in water bodies to study submerged targets. However, most models used to retrieve the bottom signal were developed for clear, shallow coastal environments (Lee et al., 1994; Lee and Carder, 2002; Mishra et al, 2005, 2007, 2006; Palandro et al., 2008; Brando et al., 2009). Semi-analytical models for estimating SAV height in inland waters such as lakes and tropical reservoirs by satellite remote sensing remains a challenge to overcome, particularly when SAV in these water bodies can survive at relatively deeper depths. SAV in Brazilian reservoirs can survive and grow at depths greater than $6 \mathrm{~m}$ (Rotta et al., 2012; 2016). Rotta et al. (2012) mapped SAV in the Porto Colômbia Reservoir (Uberaba River, Minas Gerais State) using an echosounder detecting presence of SAV up to $7 \mathrm{~m}$ depth. The densest SAV was observed by Batista et al. (2012) at depths between 2 and $4 \mathrm{~m}$ in Taquaruçu reservoir (Paranapanema River, between Paraná and São Paulo State), showing SAV growing even at the depth range of 6-8 m. The status of SAV in Nova Avanhandava Reservoir (Tietê River, São Paulo State) was analyzed by Rotta et al. (2016) who reported their occurrence at depths up to $9 \mathrm{~m}$. The detection of bottom signal is difficult at such deeper waters even when using in situ sensing due to the attenuation and scattering of radiation in the water column. Rotta et al. (2016) concluded that it is necessary to recalibrate and tune existing radiative transfer models with lots of field data in order to achieve the desired accuracy in mapping SAV biomass and height using satellite data.

The initial assumption made in this study was that benthic reflectance produced by applying radiative transfer models on satellite data may reveal the true absorption characteristics of SAV canopies which can then be incorporated in empirical models using existing vegetation indices (VIs) to estimate SAV heights. VIs based on red $(\sim 660 \mathrm{~nm})$ and green $(\sim 560 \mathrm{~nm})$ bands can be used in aquatic environments, such as green-red vegetation index (GRVI), Slope, and band ratio (G/R). Tucker (1979) evaluated and quantified the relationships between linear combinations of several VIs, including GRVI and $\mathrm{G} / \mathrm{R}$, and experimental plot biomass, leaf water content, and chlorophyll content. Motohka et al. (2010) evaluated GRVI as a phenological indicator for several representative ecosystems in Japan. It was able to detect subtle differences in the middle of the growing period for accurately classifying ecosystem types. The sensitivity of chl- $a$ scattering at green to chl- $a$ absorption at red is the underlying foundation of the Slope model (Mishra and Mishra, 2010). The simple ratio between reflectance at NIR and Red has been used in numerous studies as an indirect method of measuring vegetation biophysical properties such as leaf area index (LAI) (Jordan, 1969; Jensen, 2009). The simple ratio (NIR/R) from Landsat TM data was correlated to ground-based 
measurements of LAI in boreal conifer forests (Chen and Cihlar, 1996). Based on the same principle, the ratio between Green and Red (G/R) benthic reflectance could be tested in models to retrieve SAV heights.

Monitoring SAV heights using field survey based hydroacoustic data is a common practice (Sabol et al., 2002). Echosounder has been used for SAV mapping, providing different biophysical measurements such as canopy height, ECH (Effective Canopy Height) and biovolume (Rotta et al., 2012). These kinds of surveys, mainly for moderate to large water bodies, can be both expensive and time consuming. The exact cost of a sonar survey will depend on the size of the study site and spatial extent of the SAV; however, it is safe to assume that such surveys will be costlier than satellite-based methods in places where labor cost is relatively high. On a related note, high resolution satellite data other than SPOT-6 such as WorldView-3 or Planet Labs imagery can be obtained at a cheaper cost and used in a satellite-based method to map SAV because of the similarity in their band architecture. The goal of this study was therefore to explore the feasibility of radiative transfer-based bio-optical models for estimating SAV heights in the Nova Avanhandava reservoir using SPOT-6 satellite data. The specific objectives included (i) to remove the water column influence for retrieving the bottom reflectance; (ii) to calibrate vegetation indices-based models derived using benthic reflectance; and (iii) to compare the performance of SAV height models applied to in situ data and SPOT-6 multispectral satellite data. Multispectral satellite data have rarely been used and SPOT- 6 data have never been used to estimate benthic biophysical parameters such as SAV heights in inland waterbodies. Therefore, the use of radiatve transfer models to retrieve the bottom reflectance (such as Palandro et al., 2008; Dierssen et al., 2003) for estimating SAV heights, even at depths greater than $5 \mathrm{~m}$, can make an important technical and scientific contribution supporting ecological studies and the management of submerged macrophytes in inland waters.

\section{Study area}

This study was conducted in the Nova Avanhandava Reservoir, which is located in the lower course of Tietê River, São Paulo state, Brazil (Fig. 1). The reservoir, with a flooded area of $210 \mathrm{~km}^{2}$ and volume of $2.8 \times 10^{9} \mathrm{~m}^{3}$ is managed by the AES Tiete Company (http:// www.aestiete.com.br/) and has been operational since 1982. Fieldwork was carried out between June 28th and 30th, 2013 in the Bonito River, a tributary of the Tietê River. Twenty sampling points (P01-P20) were selected, eight points with SAV (P03, P05, P09, P11, P13, P15, P17 e P20) and twelve points without SAV (P01, P02, P04, P06, P07, P08, P10, P12, P14, P16, P18 e P19) (Fig. 1c). An average total suspended solids (TSS) of $1.52 \mathrm{mg} / \mathrm{L}$ (range of 0.50 to $3.90 \mathrm{mg} / \mathrm{L}$ ) and average chlorophyll- $a$ concentration of $9.69 \mu \mathrm{g} / \mathrm{L}$ (values between 3.00 and $19.84 \mu \mathrm{g} / \mathrm{L}$ ) were measured at the sampling points. The depth range between 1.4 and $5.8 \mathrm{~m}$ were observed for points with SAV and between 8.2 and $22.7 \mathrm{~m}$ for points without SAV. SAV height, water column depth, and GPS location were collected using an echosounder DT-X (BioSonics Inc., Seattle, WA, http://www.biosonicsinc.com) mounted under a boat that followed the paths indicated in yellow in Fig. 1c.

\section{Data}

\subsection{In situ data}

\subsubsection{Hyperspectral data}

Hyperspectral irradiance and radiance data were acquired using two RAMSES optical radiometers (TriOS, Rastede, Germany, http://www. trios.de) (Fig. 2). Both irradiance (ACC-VIS) and radiance (ARC-VIS) sensors have 190 channels from 320 to $950 \mathrm{~nm}$, and a spectral sampling of $3.3 \mathrm{~nm}$ with an accuracy of $0.3 \mathrm{~nm}$. A vertical profile of downwelling irradiance $\left(E_{\mathrm{d}}\right.$, in $\left.\mathrm{mW} \mathrm{m}^{-2} \mathrm{~nm}^{-1}\right)$ and upwelling radiance $\left(L_{\mathrm{u}}\right.$, in $\mathrm{mW} \mathrm{m}{ }^{-2} \mathrm{~nm}^{-1} \mathrm{Sr}^{-1}$ ) was acquired at each sampling location. $L_{\mathrm{u}}$ data were acquired with a $7^{\circ}$ field of view. $E_{\mathrm{d}}$ and $L_{\mathrm{u}}$ were collected in multiple ways at all sampling locations including just above the water surface, $E_{\mathrm{d}}\left(0^{+}\right)$and $L_{\mathrm{u}}\left(0^{+}\right)$, just below the air-water interface, $E_{\mathrm{d}}\left(0^{-}\right)$ and $L_{\mathrm{u}}\left(0^{-}\right)$, and at various depth intervals, $E_{\mathrm{d}}(\mathrm{Z})$ and $L_{\mathrm{u}}(\mathrm{Z})$, in the water column. Profile measurements were conducted at every $0.5 \mathrm{~m}$ depth interval at each sampling location with SAV, and the last reading was acquired at about $1 \mathrm{~m}$ above the SAV canopy to prevent resuspension of particles adhering to the plant (i.e., the epiphytic biomass), which could have influenced the spectral response. A depth interval of $1.0 \mathrm{~m}$ was used for locations deeper than $10 \mathrm{~m}$ up to a maximum depth equivalent to about $1 \%$ of $E_{\mathrm{d}}\left(0^{-}\right)$. An additional sensor was used to measure the global solar irradiance $\left(E_{\mathrm{s}}\right.$, in $\left.\mathrm{mW} \mathrm{m}^{-2} \mathrm{~nm}^{-1}\right)$ on the boat, normalizing the radiometric data. Cloud cover variability and changes in solar zenith angle can cause variations in incident surface irradiance, it is therefore strongly recommended that all scans be normalized to a specific scan (Mueller, 2003).

\subsubsection{Remote sensing reflectance}

Above-water remote sensing reflectance $\left(R_{\mathrm{rs}}\right)$ was computed using the in situ radiance and irradiance following the method proposed by Dall'Olmo and Gitelson (2005) and Gitelson et al. (2008) (Eq. (1)).

$R_{r s}=\frac{L_{u}\left(0^{-}\right)}{E_{d}\left(0^{+}\right)} \frac{t}{n^{2}} F_{i}$

where

$L_{\mathrm{u}}\left(0^{-}\right)$: is the upwelling radiance at nadir just below-surface;

$E_{\mathrm{d}}\left(0^{+}\right)$: is the downwelling irradiance above-water;

$t:$ is the transmittance at air-water interface (0.98);

$n$ : is the refractive index of water relative to air (1.33);

$F_{i}$ : is the spectral immersion coefficient.

In situ $R_{r s}$ data were resampled to represent SPOT-6 bands so that the model calibrated based on field data could be scaled up to SPOT- 6 data. To simulate the $R_{r s}(\lambda)$ for each SPOT band centered at wavelength $\lambda$, weighted averages of the $R_{r s}$ spectrum were calculated by using spectral responses of SPOT-6 (Astrium, 2013, Fig. 3), as given below (Eq. (2)).

$R_{r s_{-} s}=\frac{\sum_{\lambda} R_{r s}(\lambda) S(\lambda)}{\sum_{\lambda} S(\lambda)}$

where $R_{r s}(\lambda)$ is the spectral remote sensing reflectance; $S(\lambda)$ is the bandspecific spectral response function of SPOT-6, and $R_{r s i}$ is the simulated $R_{r s}$ using in situ data representing SPOT-6 bands.

\subsubsection{Attenuation coefficients $-K_{d}$ and $K_{L u}$}

The $E_{d}(Z)$ and $L_{u}(Z)$ data are crucial in estimating water column attenuation coefficients. Changes in cloud cover can modify the $E_{s}$, causing uncertainties in diffuse attenuation coefficient (K) profiles. According to Mueller (2003), changes in cloud cover lead to variability of the in-water light field which must be corrected to obtain accurate estimations of optical properties from irradiance or radiance. Therefore, accurate computation of $K_{d}$ and $K_{L u}$ requires normalization of the $E_{d}(Z)$ and $L_{u}(Z)$. The normalization factor $N F(\mathrm{Z})$ for each reading was calculated as:

$\boldsymbol{N F}(\boldsymbol{Z})=\frac{E_{S}\left[t\left(0^{-}\right)\right]}{E_{s}[t(Z)]}$

where

$E_{S}\left[t\left(0^{-}\right)\right]:$is the downwelling irradiance measured for the first scan at time $t\left(0^{-}\right)$on the boat;

$E_{S}[t(Z)]$ : is the downwelling irradiance measured at time $t(\mathrm{Z})$ on the boat.

Fig. 2 shows the downwelling irradiance measured on the boat $\left(E_{\mathrm{s}}\right)$ 


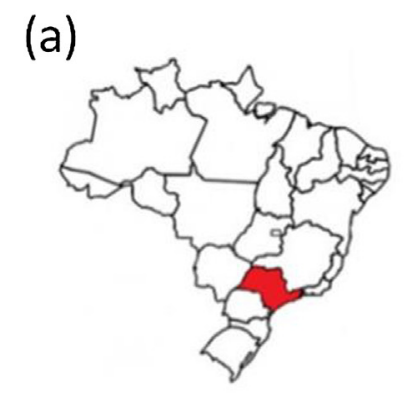

\section{BONITO RIVER
(c) Avanhandava Reservoir}

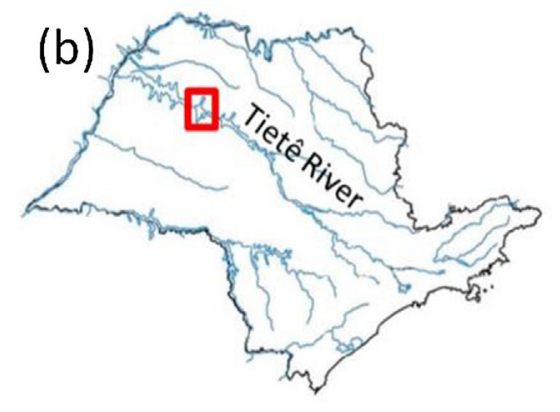

$586000 \quad 588000 \quad 590000 \quad 592000$

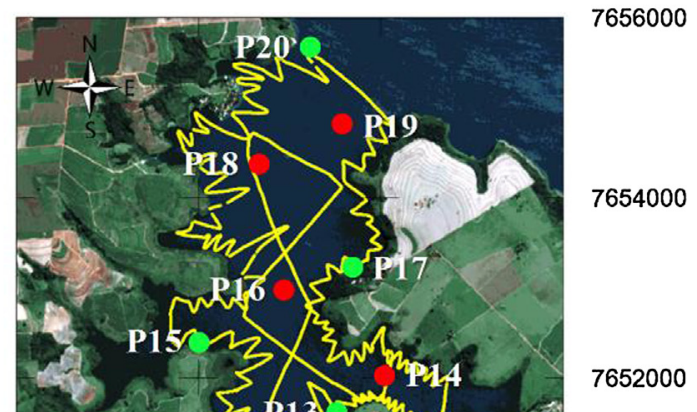

LEGEND

Sampling Point

- SAV

- No SAV

Sampling Path

Echosounder

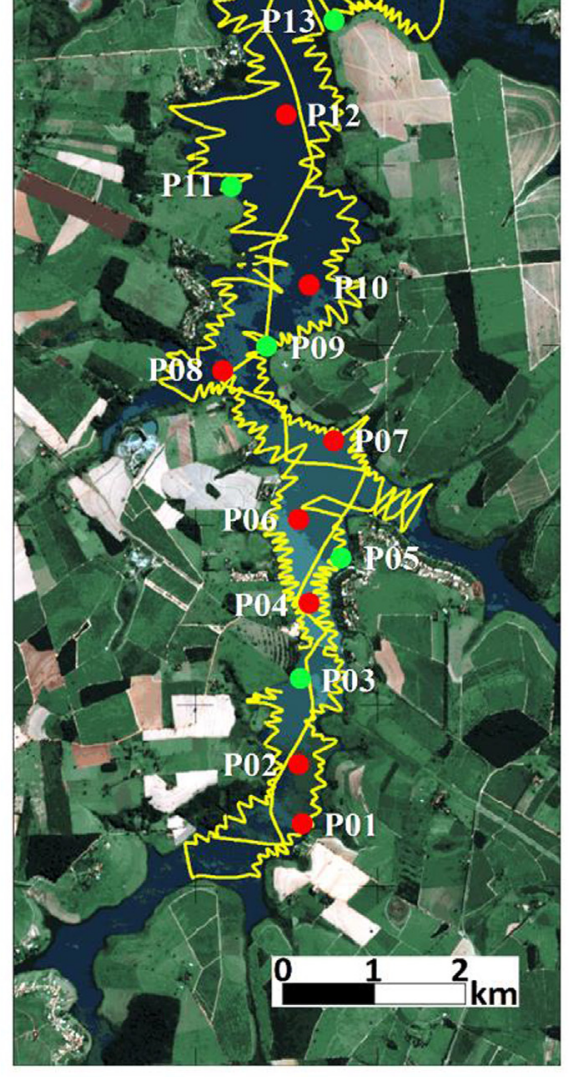

7650000

7648000

7646000

7644000

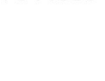

7642000

7640000

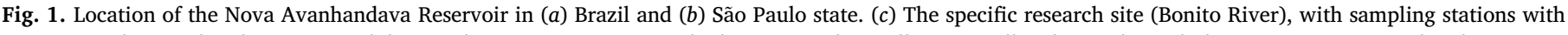

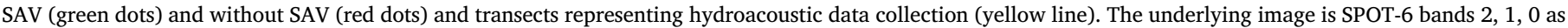

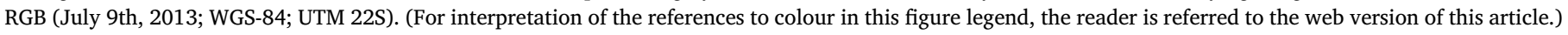

which was used to calculate $N F(\mathrm{Z})$. To normalize the spectral data and eliminate noise due to changes in illumination, Eqs. (4) and (5) can be used for $E_{d}$ and $L_{u}$ respectively.

$E_{d}^{\prime}(Z)=E_{d}(Z) N F(Z)$

$L_{u}^{\prime}(Z)=L_{u}(Z) N F(Z)$

where

$E_{d}^{\prime}(Z)$ : is the normalized downwelling irradiance at depth Z;

$E_{d}(Z)$ : is the original downwelling irradiance at depth $Z$;

$L_{u}^{\prime}(Z)$ : is the normalized upwelling radiance at depth Z;

$L_{u}(Z)$ : is the original upwelling radiance at depth $\mathrm{Z}$.

The diffuse attenuation coefficients $(K)$ were computed after the normalization procedure. $K$ is the parameter that represents the propagation of light through the water column. Diffuse attenuation coefficients of downwelling irradiance $\left(K_{\mathrm{d}}\right)$ are important for characterizing the water column because they can quantify the presence of light at different depths and determine the depth of the euphotic zone (Mishra et al., 2005). Radiance and irradiance decrease exponentially with depth, therefore, $K_{d}$ can be represented by (Mobley, 1994):

$E_{d}^{\prime}(Z)=E_{d}^{\prime}\left(0^{-}\right) e^{-K_{d} Z}$

where

$E_{d}^{\prime}\left(0^{-}\right)$: is the downwelling irradiance just below-water; Z: depth.

Analogous to Eq. (6), the attenuation coefficient of upwelling radiance, $K_{L u}$ can be written as (Mueller, 2003):

$L_{u}^{\prime}(Z)=L_{u}^{\prime}\left(0^{-}\right) e^{-K_{L u} Z}$

Palandro et al. (2008) also estimated $K_{d}$ using the $R_{\mathrm{rs}}$ from satellite 


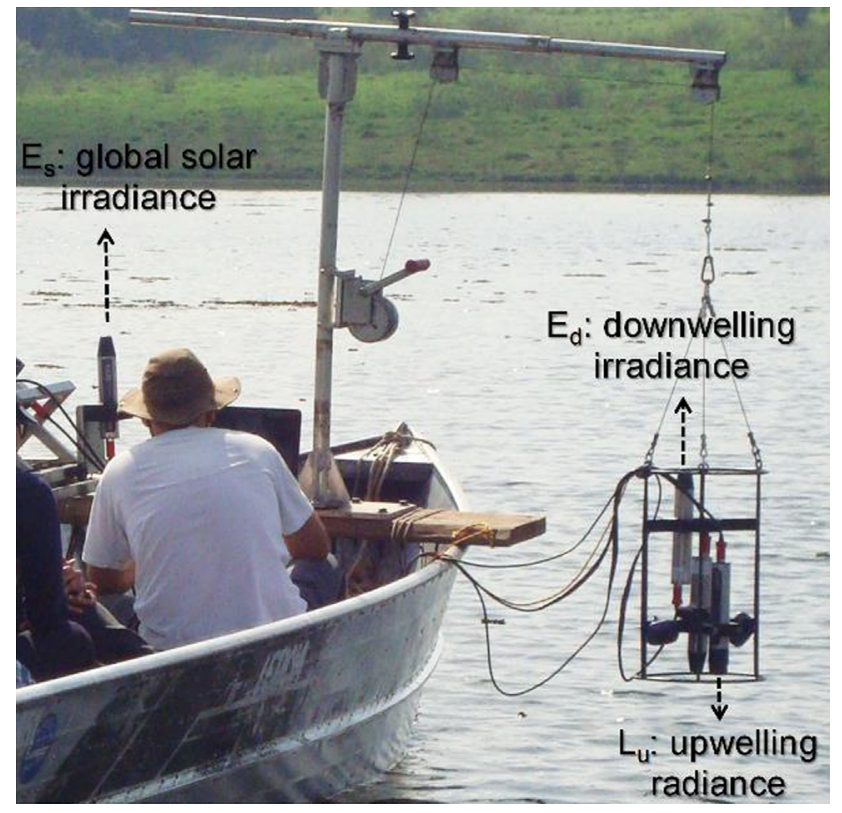

Fig. 2. Hyperspectral data collection in the field. $E_{\mathrm{s}}$ (Global solar irradiance) and $E_{\mathrm{d}}$ (Downwelling irradiance) were measured using the irradiance sensor ACC-VIS/RAMSES (TriOS, Rastede) and $L_{\mathrm{u}}$ (Upwelling radiance) was measured using the radiance sensor ARC-VIS/RAMSES (TriOS, Rastede).

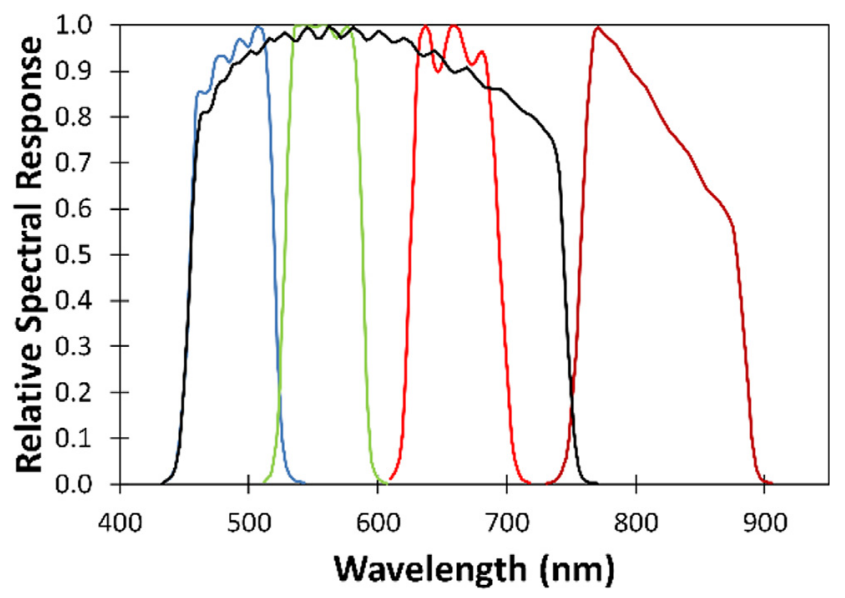

Fig. 3. Relative spectral response function of SPOT-6 (Astrium, 2013). Each spectrum represents the sensitivity of a specific band. The blue (blue line), green (green line), red (red line) and NIR (dark red line) bands have the centers at 485, 560, 660, and $825 \mathrm{~nm}$, respectively. The panchromatic band (black line) covers wavelengths between 450 and $745 \mathrm{~nm}$. (For interpretation of the references to colour in this figure legend, the reader is referred to the web version of this article.)

images $\left(R_{r s_{s} s}\right)$ and depth (Eq. (8)). In this study, $K_{d}$ is described as $K_{d}{ }^{P}$ and it was used in the models to retrieve the bottom reflectance (Eqs. (9) and (10))

$\boldsymbol{R}_{r s_{-} s}=C \times \boldsymbol{e}^{-2 K_{d} P Z}$

where

$R_{\mathrm{rs} \_}$: above-water remote sensing reflectance of image for a pixel with bottom depth Z;

C: pixel-independent constant.

The wavelengths used were green $(560 \mathrm{~nm})$ and red $(660 \mathrm{~nm})$ bands. Blue (490 nm) and near infrared (NIR) $(825 \mathrm{~nm})$ bands were not used because the blue band is strongly influenced by atmospheric scattering, while NIR goes through intense attenuation in the water column. Using these bands would have produced large errors in the model output because of the residual scattering and attenuation in Blue and NIR respectively even after implementing correction procedures.

\subsubsection{Echosounder}

Water column depth (Z) and SAV height data were collected using the scientific digital sonar DT-X (Echosounder) (BioSonics, Seattle, WA; http://www.biosonicsinc.com) during field campaigns carried out on July 4th and 5th, 2013. The transducer, notebook and GPS were connected to a surface unit with a dedicated processor for operation (Biosonics, 2004a). The echosounder transducer was vertically positioned at $0.5 \mathrm{~m}$ depth on the outside of the boat. The data collected using the echosounder were visualized in real-time via the laptop and stored in separate files for each transect. Echosounder data recorded in numerous transects are shown in Fig. 1 (yellow lines). SAV was found in many parts of the reservoir and E. densa and E. najas were the main SAV species in the Bonito River (Fig. 4a).

Visual Acquisition software (Biosonics, Seattle, WA) was used to control the acquisition of data and display echograms which describe the submerged relief depth and the presence or absence of SAV. Fig. 4b shows an echogram acquired during the fieldwork. After processing through EcoSAV software (Biosonics, Seattle, WA), an ASCII file containing the date, time of day, position (Lat, Long), depth (m), SAV coverage (\%), and mean height of the SAV (m) was generated (Biosonics, 2008). The echosounder surveys were conducted employing an appropriate spatial distribution and number of samples for the entire study area, with over 15,000 points. The echosounder was calibrated according to Biosonics recommendations (Biosonics, 2004b), using a standard target sphere of known target strength (TS). The standard target is optimized in size, material, material purity and dimensional tolerances to result in high TS accuracy and stability. This echosounder and the EcoSAV software were evaluated in advance. Biosonics digital echosounder and EcoSAV have been used in previous studies, for example, by Sabol et al. (2002) to detect SAV. Divers measured the distance between the transducer face, top of the SAV canopy, and the bottom. Ground truth exhibited close agreement between true SAV height and the hydroacoustic estimates $\left(\mathrm{R}^{2}=0.78\right) . E \operatorname{coSAV}$ was also used by Chamberlain et al. (2009), who found similar agreement between ground-truthed and hydroacoustic datasets. Moreover, they showed that the spatial differences in SAV coverage and height were accurately detected by the hydroacoustic method.

\subsection{SPOT-6 data}

SPOT-6 image acquired at 13:08:43 (GMT) on July 9th, 2013 was obtained from Airbus Defense and Space/Geo-Intelligence. SPOT-6 and SPOT-7, built by AIRBUS Defense \& Space, ensure service continuity of SPOT-4 and SPOT-5 satellites, which have been operating since 1998 and 2002. The revisit time is 1 day with SPOT- 6 and SPOT-7 operating simultaneously (Astrium, 2013). SPOT-6 has three bands in visible region and one band in near infrared (NIR): B0 (455-525 nm), B1 $(530-590 \mathrm{~nm}), \mathrm{B} 2(625-695 \mathrm{~nm})$ and B3 $(760-890 \mathrm{~nm})$. The image was acquired for Nova Avanhandava Reservoir with an across angle of $-6.6002^{\circ}$ and along angle of $19.1336^{\circ}$, in WGS-84 coordinate system. The $R_{r s}$ from SPOT-6 image is represented as $R_{r s_{-}}$.

\section{Methodology}

\subsection{Atmospheric correction of SPOT-6}

Atmospheric correction of the SPOT-6 image was performed using FLAASH (Fast Line-of-sight Atmospheric Analysis of Spectral Hypercubes) software. FLAASH is an atmospheric correction method based on MODTRAN4 (MODerate spectral resolution atmospheric TRANsmittance algorithm and computer model) code (Adler-Golden 

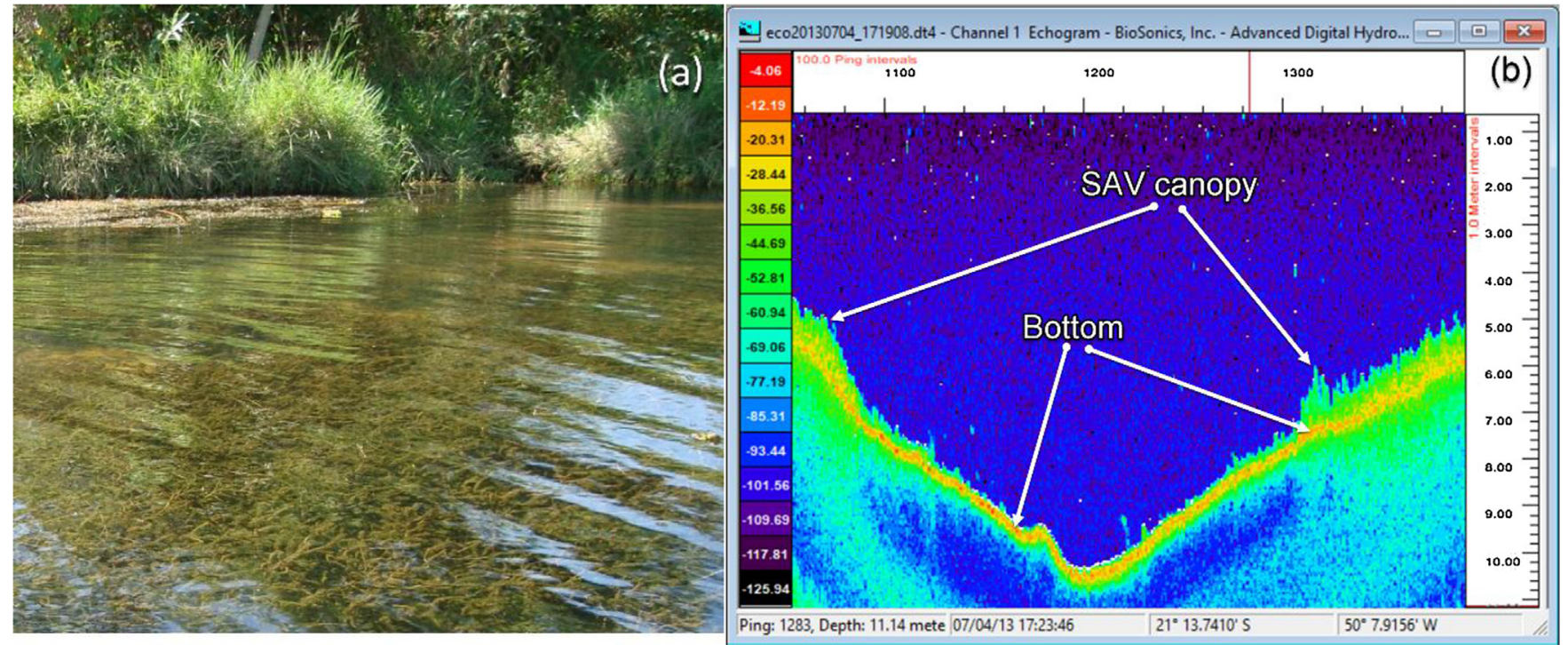

Fig. 4. (a) Area covered by SAV in the Bonito River, and (b) Echogram from echosounder Biosonics DT-X indicating regions of SAV canopy and bottom.

et al., 1999). The user must specify the appropriate input parameters that characterize the atmospheric conditions and illumination/viewing geometry at the time of image acquisition. The tropical atmospheric model and the rural aerosol model were selected. The initial visibility must be between 40 and $100 \mathrm{~km}$ if the weather condition is clear (ITT, 2009). Based on an empirical iterative approach, an initial visibility of $70 \mathrm{~km}$ was established. Others input parameters were set as, sensor altitude: $695 \mathrm{~km}$, ground elevation: $362 \mathrm{~m}$ from msl, zenith angle: $161.5^{\circ}$ and azimuth angle: $195^{\circ}\left(-165^{\circ}\right)$.

\subsection{Bottom reflectance}

In Nova Avanhandava Reservoir, SAV was found up to $10 \mathrm{~m}$ depth (Rotta et al., 2016), therefore, removing the water column response from the remote sensing signal is fundamental to retrieving bottom reflectance for SAV height mapping and analysis. Two different models for retrieving bottom reflectance from $R_{r s}\left(R_{r s_{-} i}\right.$ and $\left.R_{r s_{s}}\right)$ were used and compared. The first method was proposed by Palandro et al. (2008) in which $K_{d}$ is used to remove the water-column attenuation effect from $R_{r s}$ in order to isolate the remote sensing reflectance of the bottom $\left(R_{r s}{ }^{b}\right)$ (Eq. (9)). The second method is derived from Beer's Law to retrieve the irradiance reflectance $\left(E_{u} / E_{d}\right)$ of the bottom $\left(R^{b}\right)$ proposed by Dierssen et al. (2003) (Eq. (10)). Hereafter, the models are referred to as PAL08 and DIE03. Average values of $K_{d}$ and $K_{L u}$ for each band were used in Eqs. (9) and (10) to derive bottom reflectance. The performance of both models was compared. The green $(560 \mathrm{~nm})$ and red $(660 \mathrm{~nm})$ bands, simulated for SPOT-6, were also used to retrieve the bottom using $K_{d}^{P}$.

$R_{r s}{ }^{b}=\frac{R_{r s}}{0.54} \exp \left(-2 K_{d} Z\right)$

where

$R_{r s}{ }^{b}$ : remote sensing reflectance of the bottom;

$R^{b}=\frac{R_{r s} Q_{b}}{t} \frac{\exp \left(-K_{L u} Z\right)}{\exp \left(-K_{d} Z\right)}$

where

$R^{b}$ : irradiance reflectance of the bottom;

$Q_{b}:$ ratio $E_{\mathrm{u}} / L_{\mathrm{u}}$ at the bottom interface and was assumed to be $\pi$; $t$. transmittance of upwelling radiance and downwelling irradiance across the air-water interface and was assumed as 0.54 (MOBLEY, 1994).

\subsection{SAV height estimation}

Chlorophyll- $a$ and $b$ are two of the most important pigments that absorb light in the blue and red bands for vegetation photosynthesis. Green light is absorbed less compared with the red and blue bands which results in a reflectance peak around $550 \mathrm{~nm}$ (Mobley, 1994; Kirk, 2011). Absorption characteristics of plant canopies can be incorporated in empirical models using vegetation indices (VIs) to identify stress, biomass, productivity and other biophysical traits (Jensen, 2009; Ghosh et al., 2016). Three VIs based on SPOT-6 derived $R_{r s}{ }^{b}$ and $R^{b}$ at red $(660 \mathrm{~nm})$ and green $(560 \mathrm{~nm})$ bands were used to calibrate the SAV height models including a green-red vegetation index (GRVI, Eq. (11)), a Slope model (Eq. (12)), and a band ratio (G/R, Eq. (13)). These indices have been widely used to study terrestrial vegetation (Tucker, 1979; Motohka et al., 2010; Falkowski et al., 2005; Hunt et al., 2005; Mishra et al., 2012). Although submerged, SAV presents structures similar to terrestrial vegetation, so the VIs developed for a terrestrial environment were assumed to work for submerged aquatic plants provided necessary water column corrections have been implemented on the remote sensing data.

$G R V I=\frac{R_{560}-R_{660}}{R_{560}+R_{660}}$

Slope $=\frac{R_{560}-R_{660}}{660-560}$

$G / R=\frac{R_{560}}{R_{660}}$

$R_{560}$ is the reflectance in green and $R_{660}$ the reflectance in red bands. $R$ is replaced by $R_{r s}{ }^{b}$ derived from PAL08 (Eq. (9)) or $R^{b}$ from DIE03 (Eq. (10)). Ultimately the bottom reflectance data by PAL08 and DIE03 were used in three indices (GRVI, Slope and $G / R$ ) to calibrate a model for estimating SAV height. The model calibration was performed using: (a) the simulated SPOT-6 bands from hyperspectral in situ data $\left(R_{r s i}\right)$, and (b) the SPOT-6 image $\left(R_{r s s}\right)$.

The in situ SAV height models were calibrated based on eight points (Fig. 1 - green dots) collected in the field campaign using a spectroradiometer, where the $R_{r s}$ were resampled to SPOT-6 bands $\left(R_{r s i}\right)$. Due to the low number of in situ sample points, validation was performed on the $R_{r s_{s} s}$ from 100 random SPT- 6 pixels at locations with SAV (indicated by the echosounder). In other words, the calibrated model with the eight points was applied to the $100 R_{r s s}$ SPT- 6 pixels selected for the comparison between estimated (in situ model) and true (echosounder) 
SAV height values. The calibration and validation of the SPOT-6 imagebased SAV height models was performed using $206 R_{r_{s} s}$ pixels from locations with SAV. Out of these 206 pixels, 106 were used in calibration (model fit) and 100 pixels were used for validation (the same pixels used in in situ SAV height model validation as described in the previous section).

The models were evaluated based on $R^{2}, p$-value, root mean squared error (RMSE) (Eq. (14)), normalized root mean squared error (NRMSE) (Eq. (15)) and bias (Eq. (16)). The RMSE, NRMSE and Pbias were calculated just for models with significant $p$-value $(p<0.05)$.

$R M S E=\sqrt{\frac{\sum_{i=1}^{n}\left(y_{i}-\hat{y}_{i}\right)^{2}}{n}}$

NRMSE $=\frac{R M S E}{y_{\max }-y_{\min }}$

bias $=\frac{\sum_{i=1}^{n}\left(y_{i}-\widehat{y}_{i}\right)}{\sum_{i=1}^{n} y_{i}}$

where

$y_{i}:$ is the measured value for the $i$ observation;

$\hat{y}_{i}$ : is the estimated value for the $i$ observation;

$y_{\max }$ : is the maximum observed value;

$y_{\text {min }}:$ is the minimum observed value.

Finally, both in situ data and SPOT- 6 based models were applied to the satellite image in order to estimate and map SAV height for the entire study area. A mask was prepared based on echosounder data to identify two regions, with and without SAV. The models were applied only to the region with SAV.

\section{Results and discussion}

\subsection{Remote sensing reflectance}

$R_{r s}$ calculated using Eq. (1) is shown in Fig. 5a for points without SAV, Fig. 5b for points with SAV and Fig. 5 c for the SPOT- 6 bands simulated $\left(R_{r s s}\right)$ for points with SAV. The most discrepant curve is P04 (point without SAV), showing high values of $R_{r s}$ between green and red spectral regions. There was higher TSS concentration, about $2 \mathrm{mg} \mathrm{L}^{-1}$, at P04 and it had the highest value of $K_{d}$ PAR - photosynthetic active radiation (about $1.5 \mathrm{~m}^{-1}$ ) (data not shown), which explains the higher $R_{r s}$ in 560-700 nm. Points P12, P14, P16 and P19 (without SAV) presented a smooth reflectance peak at around $700 \mathrm{~nm}$, which might indicate the presence of phytoplankton. The chl- $a$ concentrations were greater than $13 \mu \mathrm{g} \mathrm{L}^{-1}$ at these points. Rundquist et al. (1996) and many other studies have verified high red-edge-NIR reflectivity of algal chlorophyll in their experiments. $R_{r s}$ at other points without SAV did not show a red-edge-NIR peak due to low chl- $a$ (between 3.0 and $\left.9.9 \mu \mathrm{g} \mathrm{L}^{-1}\right)$.

A general decrease in the magnitude of $R_{r s}$ for SAV points was observed from upstream to downstream locations, (i.e., from P03 to P20). This behavior is strongly correlated with the spatial distribution of TSS concentration, which exhibits the highest values in the upstream region of the river. According to Jensen (2009), from 580 to $690 \mathrm{~nm}$ and NIR $(\sim 800 \mathrm{~nm})$ reflectance increases if suspended matter increases. Therefore, high overall $R_{r s}$ at upstream locations could be a result of high backscattering of TSS. A prominent reflectance peak near $700 \mathrm{~nm}$ observed at SAV locations such as P20 indicates shallow water $(1.4 \mathrm{~m}$ for P20) with a strong bottom signal mainly from vegetation. This is because a prominent $700 \mathrm{~nm}$ reflectance peak, a proxy for chl- $a$ scattering, indicates dominance of chl- $a$ signal in $R_{r s}$ either due to chl- $a$ from phytoplankton cells floating in the water column or chl- $a$ from SAV in optically shallow areas. The points with SAV, except for P20, are at depths between 2.8 and $5.8 \mathrm{~m}$, which hinder the identification of spectral features in $R_{\mathrm{rs}}$ curves indicating the presence of SAV. Similar curves were presented by Watanabe et al. (2013) in regions of 2 to $3 \mathrm{~m}$ of water column overlying the SAV canopy in another Nova Avanhandava Reservoir tributary. As shown in Fig. 5a and b, the difference between $R_{r s}$ at points with SAV and without SAV is practically imperceptible at relatively deeper regions. Therefore, bottom retrieval is strongly recommended.

The simulated SPOT bands $\left(R_{r s_{-}}\right)$presented similar shape compared to in situ $R_{\mathrm{rs}}$; however, several spectral details were lost due to the generalization. $R_{r s}$ in the region around $700 \mathrm{~nm}$, important for identification of chl- $a$ in vegetation, was lost because of the lack of a band in SPOT- 6 for this range. The curves maintained the reflectance values in the green $(560 \mathrm{~nm})$ and red $(660 \mathrm{~nm})$ bands even considering the wide bandwidth of SPOT-6. The relationship between the green and red bands was therefore preserved, which means the output of the equations using 560 and $660 \mathrm{~nm}$ from SPOT-6 data may present similar results as in situ and $R_{r_{-} i}$ data.

\subsection{Attenuation coefficients $-K_{d}$ and $K_{L u}$}

The attenuation coefficients, $K_{d}$ and $K_{L u}$, must be known to determine the relationship between $R_{r s}$ and $R_{r s}{ }^{b}$ or $R^{b}$. The attenuation coefficient of upwelling and downwelling flux is not equivalent, because of the influence of signal originating from the bottom (Maritorena et al., 1994). According to Dierssen et al. (2003), the upwelling flux from the bottom is theoretically always greater than $K_{d}$, because the bottom makes the angular structure of the light more isotropic. Fig. 6 shows $K_{d}$ (a) and $K_{L u}$ (b) derived from in situ $E_{d}$ and $L_{u}$ data at locations with SAV. Fig. $6 \mathrm{c}$ displays $K_{d}^{P}$, that is the $K_{d}$ derived as the slope of linear regression between depth and $\ln R_{r s_{-} s}$ (Palandro et al., 2008) from the SPOT-6 image.

Strong absorption was noted for $K_{d}$ and $K_{L u}$ at $400-450 \mathrm{~nm}$ (Fig. 6a and $6 \mathrm{~b}$ ), which may be caused by the presence of chl- $a$ in the water and mainly CDOM (Colored Dissolved Organic Matter). A peak was observed at $650-700 \mathrm{~nm}$ for $K_{L u}$, which may indicate the presence of chl- $a$ in the water, besides the upwelling signal from SAV on the bottom. Lower values were detected between 550 and $600 \mathrm{~nm}$, and there was an increase in $K_{d}$ and $K_{\mathrm{Lu}}$ above $600 \mathrm{~nm}$, due to pure water absorption which is higher in red and NIR, as presented by Pope and Fry (1997). Chl- $a$ absorption is characterized by strong absorption in the blue and red spectral regions, peaking at 430 and $665 \mathrm{~nm}$, respectively, with very little absorption in the green (Mobley, 1994). According to Kirk (2011), in inland waters, blue wavelengths are usually the most strongly attenuated, due to the higher levels of CDOM typically found in this kind of environment. Green light is usually the most penetrating wavelength in inland water, followed by red.

The linear models between $\ln R_{r s_{-} s}$ and depth presented satisfactory fits. However, $K_{d}^{P}$ values were significantly lower than $K_{d}$. Palandro et al. (2008) used high reflectance bottom type (sand) at different depths in a coastal area and assumed a negligible contribution of the shallow-water column to the total signal for calculating $K_{d}^{P}$. In this study, the presence of different SAV height on the bottom of the study area causes absorption of light with diverse magnitudes. Also, suspended solids and chl- $a$ have strong interference on water absorption and scattering. Consequently, the $K_{d}^{P}$ value calculated from $R_{r s_{-} s}$ in Nova Avanhandava was lower than $K_{d}$. However, $K_{d}^{P}$ was used to test its performance in models for retrieving $R_{r s}{ }^{b}$ and $R^{b}$.

\subsection{Atmospheric correction of SPOT image}

Atmospheric correction is generally evaluated by comparing $R_{r s}$ spectra from the images before (top of atmosphere - TOA) and after the procedure at all sampling locations and comparing the pixels after atmospheric correction with corresponding ground-based measurements (Mishra et al., 2007). Significant decreases in reflectance after atmospheric correction are noted for $R_{r s}$, mainly in the blue band, caused by 

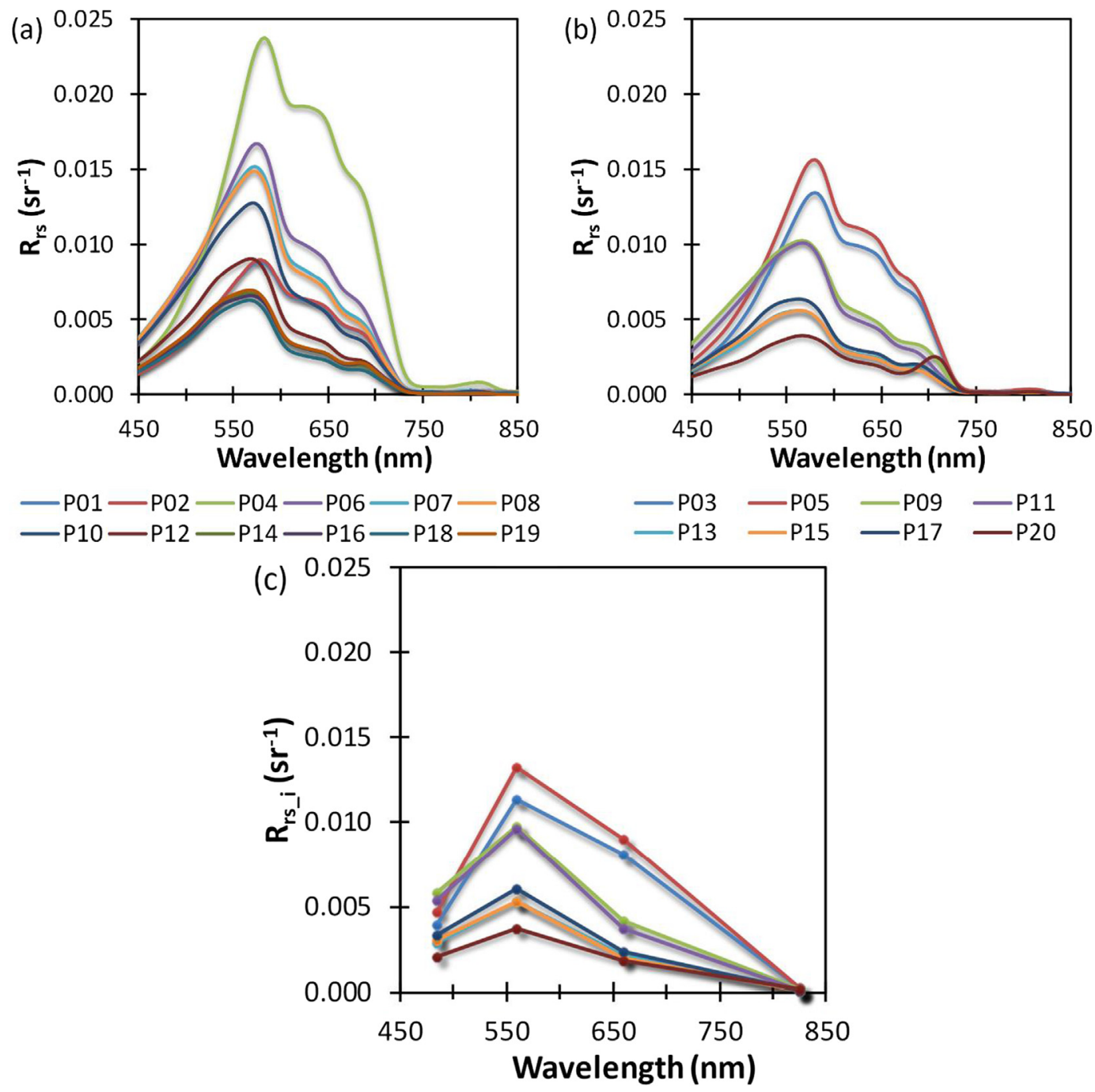

$$
\rightarrow \text { P03 } \rightarrow \text { P05 } \rightarrow \text { P09 } \rightarrow \text { P11 }
$$

Fig. 5. (a) In situ $R_{r s}$ for sample points without SAV, (b) in situ $R_{r s}$ for the sample points with SAV, and (c) $R_{r s i}$ simulated bands of SPOT 6 for points with SAV.

a strong Rayleigh scattering in the atmosphere. The $R_{r s}$ decrease at red and NIR bands is due to high absorption by the water itself. A peak in the green band is observed after atmospheric correction, which indicates the presence of chlorophyll and other absorbing components in the water (Fig. 7).

In situ $R_{r s}$ spectra acquired by RAMSES/TriOS sensors were simulated to match the SPOT- 6 sensor bands $\left(R_{r s_{-}}\right)$and were compared with SPOT-6 atmospherically corrected $R_{r s s}$ at sampling points with different
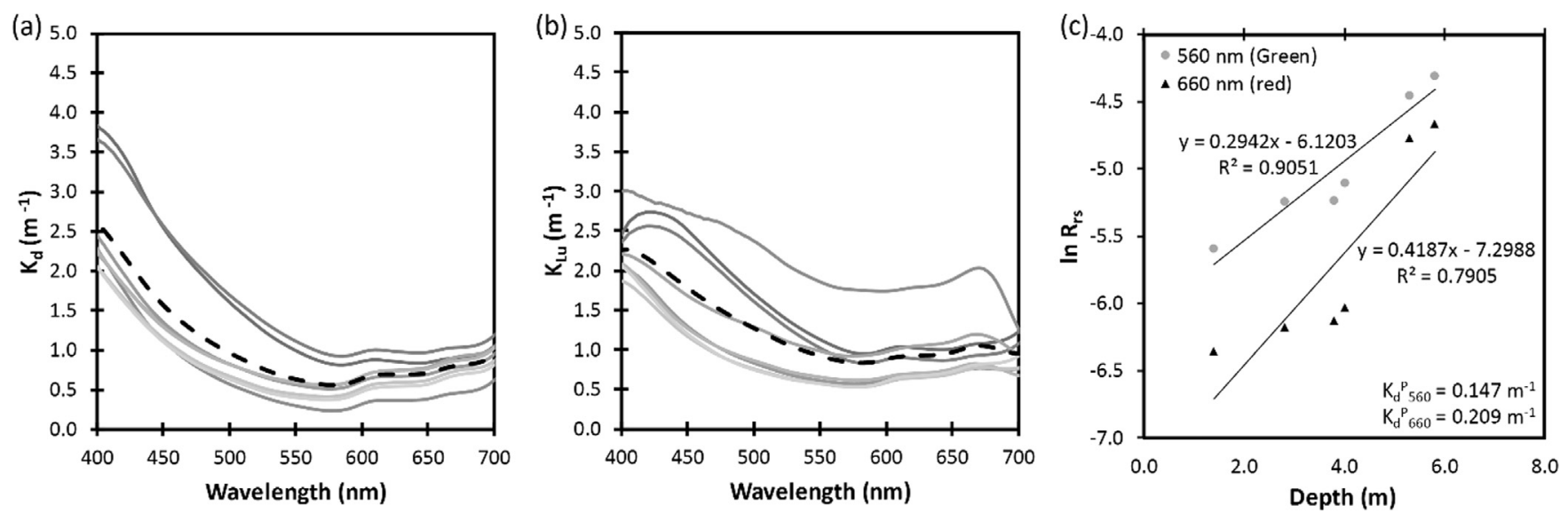

Fig. 6. (a) $K_{d}$ derived from $E_{d}$, (b) $K_{L u}$ derived from $L_{u}$. Dashed lines represent the average values. (c) Scatter plot between $R_{r s i}$ and depth to obtain $K_{d}^{P}$ using green and red bands according to Palandro et al. (2008). 
(a)

SPOT - Before Atmospheric Correction

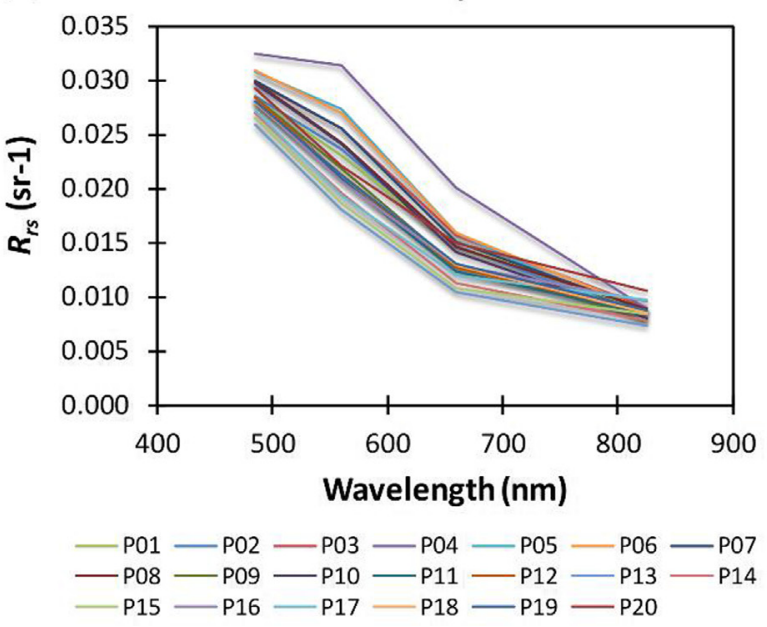

(b)

SPOT - After Atmospheric Correction

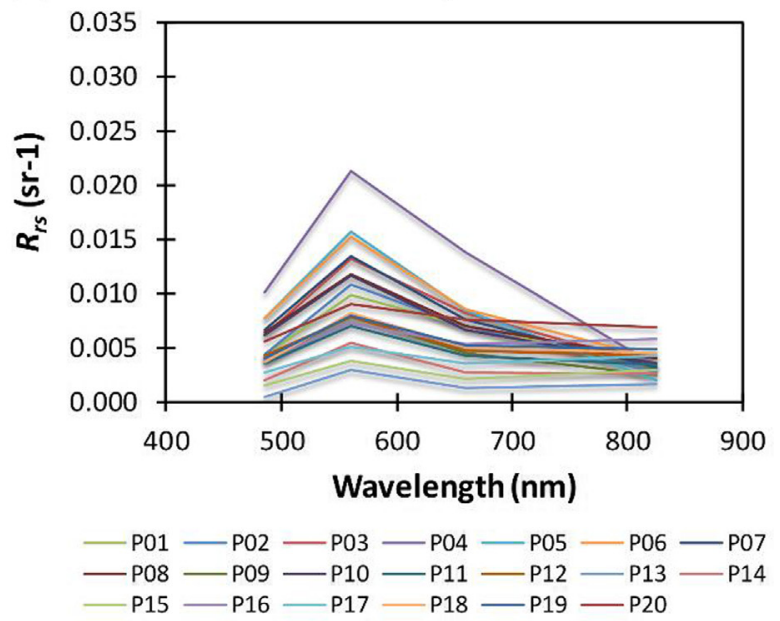

Fig. 7. $R_{r s}$ of SPOT-6 bands at all sampling locations (a) before (TOA) and (b) after FLAASH atmospheric correction.
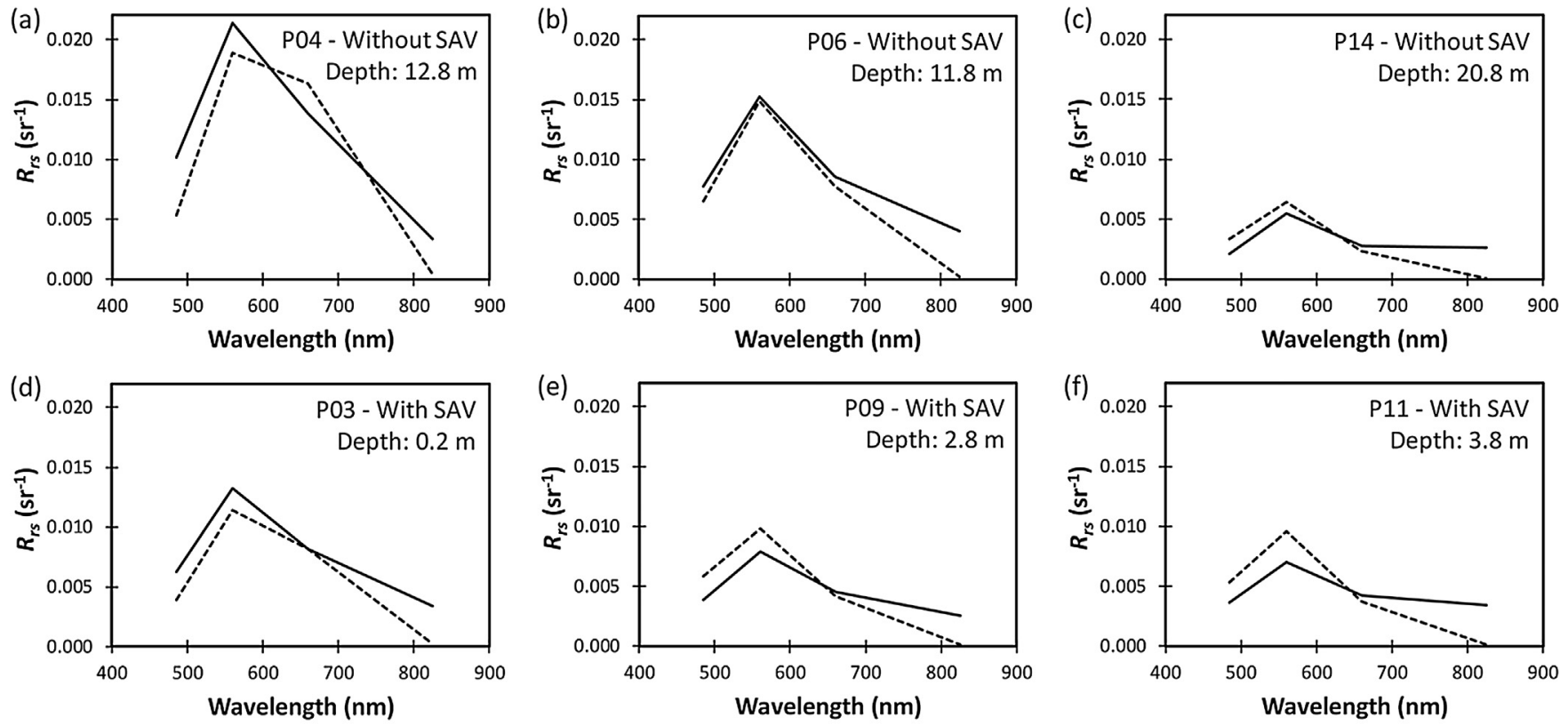

--.-- $R_{r s_{-} i}$ (in situ data) $\quad-R_{r s_{-} s}$ (SPOT-6 image)

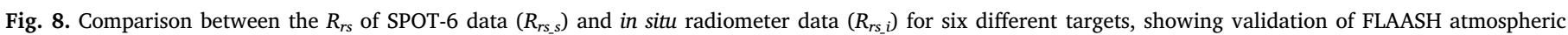
correction model; (a), (b) and (c) are reflectance data acquired at deep water locations without SAV; (d), (e) and (f) are reflectance at locations with SAV.

conditions of water quality and bottom for performance validation (Fig. 8). As described in the sections above, P04 (Fig. 8a) shows the maximum $R_{r s}$ value most likely due to the high concentration of suspended solids (Secchi depth $=0.8 \mathrm{~m}$ ). P06 (Fig. 8b) is close to P04, however, it has a lower concentration of suspended solids (Secchi depth $=2.6 \mathrm{~m}$ ), which decreases the $R_{r s}$ value. P14 (Fig. $8 \mathrm{c}$ ) has the lowest $R_{r s}$ values compared to other points without SAV (Fig. 8a and $8 \mathrm{~b}$ ), because of the high transparency of the water column (Secchi depth $=4.2 \mathrm{~m}$ ) even at greater depths. Fig. 8d (P03), 8e (P09) and $8 \mathrm{f}$ (P11) represent the $R_{r s}$ acquired at shallow points with SAV. $R_{r s}$ at P03 (Fig. 8d) was higher than $R_{r s}$ at P09 and P11, probably because of the low SAV height of $0.2 \mathrm{~m}$ (lower SAV height may absorb less radiation than higher SAV height) and high suspended solids concentration (closer to P04, with lower Secchi depth). P09 (Fig. 8e) and P11 (Fig. 8f) have depths of 2.8 and $3.8 \mathrm{~m}$, respectively, and SAV height of 0.7 (P09) and $1.2 \mathrm{~m}$ (P11). Due to their similarity, the $R_{r s}$ values at P09 and P11 were similar.

\subsection{Bottom reflectance}

$R_{r s}{ }^{b}$ and $R^{b}$ represent bottom reflectance after removing attenuation by the water column. Fig. 9 represents the bottom reflectance of simulated SPOT- 6 green and red bands (bands used to calculate the indices - Eqs. (11), (12) and (13)) based on PAL08 and DIE03. PAL08 and DIE03 models produced different shapes of bottom reflectance spectra. The main difference between PAL08 and DIE03 was the use of $K_{L u}$ by DIE03, indicating that the upwelling and downwelling irradiance are not equal, and therefore, the incorporation of $K_{L u}$ in bottom retrieval process is important.

Different slopes between the green and red bands were observed in $R_{r s}{ }^{b}$ from Fig. 9a (PAL08, using $K_{d}$ ) for all points, with greater value at P20, followed by P09 and P15. However, this decrease in slope did not accord with the observed SAV height (data not shown). Due to the exponential behavior of PAL08 (Eq. (9)), $K_{d}$ (or $K_{d}^{P}$ ) exerts a direct influence on the $R_{r s}{ }^{b}$ values (Palandro et al., 2008). Since $K_{d}{ }^{P}$ values are 

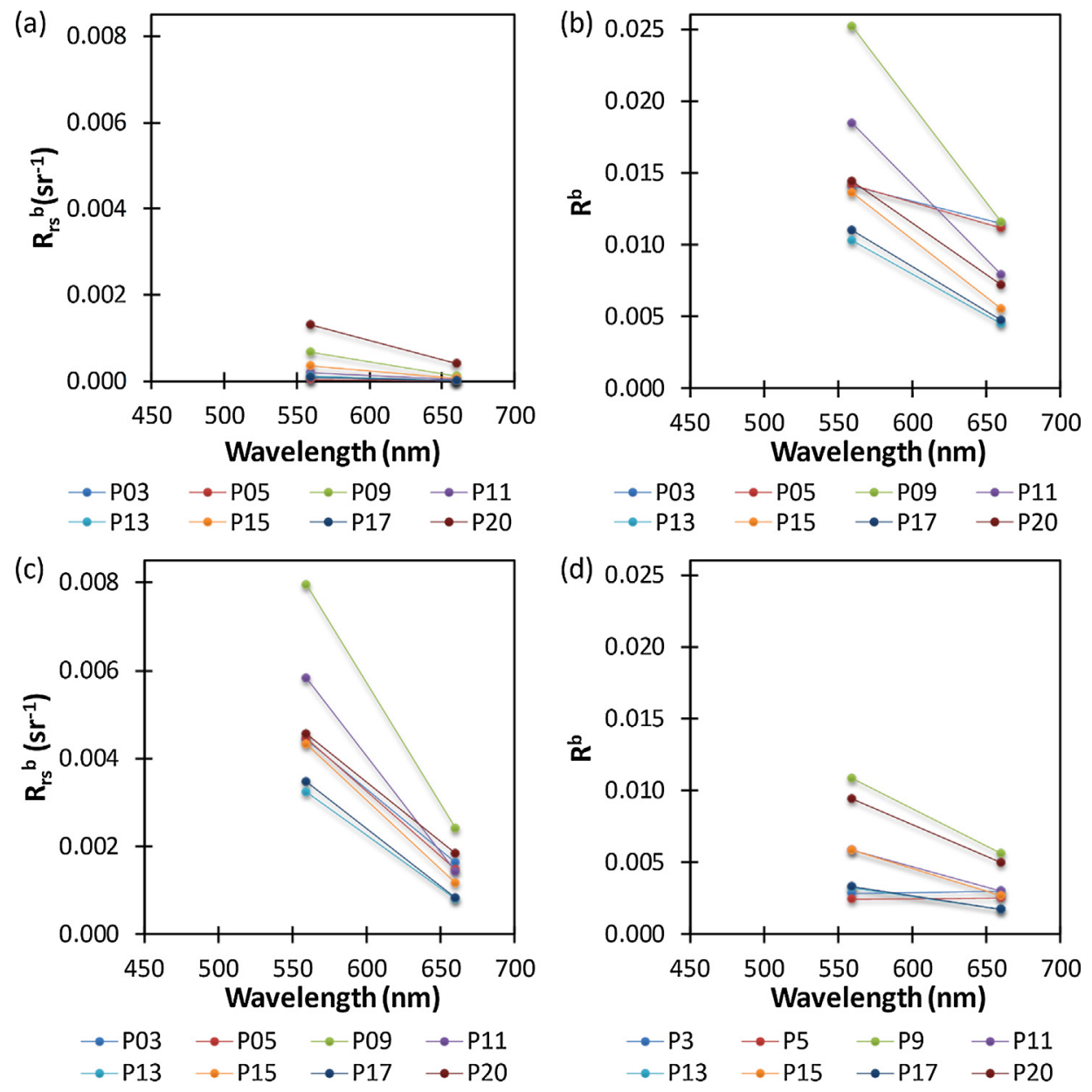

Fig. 9. (a) $R_{r s}{ }^{b}$ retrieved by PAL08 and (b) $R^{b}$ retrieved by DIE03, using $K_{d \cdot}$. (c) $R_{r s}{ }^{b}$ retrieved by PAL08 and (d) $R^{b}$ retrieved by DIE03, using $K_{d}{ }^{P}$.

much lower than $K_{d}$, PAL08 $R_{r s}{ }^{b}$ based on $K_{d}{ }^{P}$ (Fig. 9c) are greater than PAL08 $R_{r s}{ }^{b}$ using $K_{d}$ (Fig. 9a). P03 and P05 presented similar $R^{b}$ values for green and red bands from DIE03 model (Fig. $9 \mathrm{~b}$ and d) (i.e., low slope), probably influenced by the high concentration of suspended solids in that region. Based on Eq. (10), the higher the $K_{d}$ value, the greater the $R_{b}$ value, if $K_{L u}$ remains constant. And because $K_{d}$ is greater than $K_{d}^{P}$, and $K_{L u}$ is constant, DIE03 $R^{b}$ obtained using $K_{d}^{P}$ (Fig. 9d) is higher than DIE03 $R^{b}$ using $K_{d}$ (Fig. 9b). The high difference between green and red reflectance for P20, P15, and P09 in Fig. 9d was highlighted, since they are at depths between 1.4 and $2.8 \mathrm{~m}$, and with tall SAV height.

\subsection{Estimation of SAV height}

PAL08 $R_{r s}{ }^{b}$ and DIE03 $R^{b}$ and the SAV height data from echosounder were used to calibrate SAV height models. Two types of model empirical were developed, SAV models using SPOT-6 simulated in situ data $\left(R_{r s_{-}}\right)$; and models using atmospherically corrected SPOT-6 data $\left(R_{r s_{-}}\right)$.

\subsubsection{In situ $S A V$ height models}

PAL08 $R_{r s}^{b}$ and DIE03 $R^{\mathrm{b}}$ retrieved using $R_{r s i}$ data from the eight sampling locations with SAV (shown in Fig. 1) were used in the in situ SAV height model calibration. Table 1 shows the performance of models based on the VIs, such as GRVI, Slope and G/R. The validation was performed using 100 pixels collected randomly from SPOT image at locations with SAV. All SAV height models based on PAL08 $R_{r s}{ }^{b}$ (from $\alpha 1$ to $\alpha 6$ ) presented $R^{2}$ values lower than 0.3 ; moreover, $p$-values were not significant $(p<0.05)$, ranging from 0.187 to 0.787 . These results may indicate that the PAL08 model was not suitable for retrieving the bottom in inland waters, since the relationship between the VIs from $R_{r s}^{b}$ (or $R^{b}$ ) and SAV height was not significant. On the other hand, SAV height models based on DIE03 $R^{\mathrm{b}}$ were significant with strong correlation for most VIs except for Slope model (i.e., $\alpha 8$ and $\alpha 11$ ). In addition, SAV model $\alpha 7$, which uses GRVI, produced negative estimation during validation.

The $\alpha 7$ and $\alpha 10$ presented similar performance compared to $\alpha 9$ and $\alpha 12$ ( $\mathrm{R}^{2}, \mathrm{RMSE}$, NRMSE and Pbias), however models based on simple two-band ratio, $G / R$ were chosen mainly because of the simplicity in VI calculation and also to cancel out any residual error propagated in the bottom reflectance calculations. Both models, $\alpha 9$ and $\alpha 12$, showed similar performance with RMSE of $0.52 \mathrm{~m}$ and $0.58 \mathrm{~m}$ respectively (Fig. 10). Tucker (1979) similarly evaluated the relationship between various VIs and blue grama grass based on in situ data. Using the simple ratio $G / R$, the author obtained $\mathrm{R}^{2}$ of $0.78,0.82$ and 0.75 for total chlorophyll, total wet biomass and total dry biomass respectively, demonstrating the potential of $\mathrm{G} / \mathrm{R}$ in vegetation studies. Even though $K_{d}^{P}$ calculated based on $R_{r s_{-} s}$ as proposed by Palandro et al. (2008) has exhibited high accuracy in ocean waters, it did not present convincing results for this study area, probably because of the interference due to the presence of SAV on the bottom and a higher concentration of total suspended solids and chlorophyll- $a$ when compared to oceanic environments.

\subsubsection{SPOT-6 SAV height models}

PAL08 $R_{r s}{ }^{b}$ and DIE03 $R_{b}$ retrieved from 108 random pixels with SAV were used to compute GRVI, Slope and G/R and calibrate the SAV height models (see Table 2). The validation was performed using the same 100 pixels for in situ SAV height model (i.e., 100 pixels with SAV 
Table 1

SAV height model calibration $(\mathrm{n}=8)$ and validation $(\mathrm{n}=100)$ results using SPOT-6 simulated in situ $R_{r s_{-} i}$ data.

\begin{tabular}{|c|c|c|c|c|c|c|c|}
\hline$R_{r s}^{b}$ or $R^{b}$ & Model & Equation & $R^{2}$ & $p$-value & RMSE (m) & NRMSE (\%) & Pbias (\%) \\
\hline \multirow[t]{3}{*}{ PAL08 $\left(K_{d}\right)$} & $\alpha 1$ & $\mathrm{SAV}=-1.34(G R V I)+1.8727$ & 0.0773 & 0.505 & - & - & - \\
\hline & $\alpha 2$ & SAV $=53200($ Slope $)+0.7273$ & 0.1340 & 0.373 & - & - & - \\
\hline & $\alpha 3$ & $\mathrm{SAV}=-0.0485(G / R)+1.2405$ & 0.0565 & 0.571 & - & - & - \\
\hline \multirow[t]{3}{*}{ PAL08 $\left(K_{d}^{P}\right)$} & $\alpha 4$ & $\mathrm{SAV}=2.8635(G R V I)-0.676$ & 0.2150 & 0.247 & - & - & - \\
\hline & $\alpha 5$ & $\mathrm{SAV}=-4786.7($ Slope $)+1.032$ & 0.0131 & 0.787 & - & - & - \\
\hline & $\alpha 6$ & $\mathrm{SAV}=0.3476(G / R)-0.3266$ & 0.2700 & 0.187 & - & - & - \\
\hline \multirow[t]{3}{*}{$\operatorname{DIE03}\left(K_{d}, K_{L u}\right)$} & $\alpha 7$ & $\mathrm{SAV}=2.9759(G R V I)-0.0717$ & 0.7377 & 0.006 & 0.52 & 27.2 & 59.5 \\
\hline & $\alpha 8$ & SAV $=4765.8($ Slope $)+0.5321$ & 0.1508 & 0.342 & - & - & - \\
\hline & $\alpha 9$ & $\mathrm{SAV}=0.7877(G / R)-0.7118$ & 0.7282 & 0.007 & 0.52 & 27.0 & 57.3 \\
\hline \multirow[t]{3}{*}{$\operatorname{DIE03}\left(K_{d}^{P}, K_{L u}\right)$} & $\alpha 10$ & $\mathrm{SAV}=2.4595(G R V I)+0.2857$ & 0.7502 & 0.005 & 0.54 & 28.0 & -46.4 \\
\hline & $\alpha 11$ & $\mathrm{SAV}=12060($ Slope $)+0.5929$ & 0.2662 & 0.191 & - & - & - \\
\hline & $\alpha 12$ & $\mathrm{SAV}=0.8352(G / R)-0.5578$ & 0.7506 & 0.005 & 0.58 & 30.2 & -50.0 \\
\hline
\end{tabular}

collected randomly from the SPOT image). As opposed to the in situ SAV height models, most of the SPOT- 6 models including PAL08 models produced significant $p$-values (lower than 0.05), except for $\beta 5, \beta 10$ and $\beta 12$. Models, $\beta 1$ to $\beta 6$, based on PAL08 did not yield an adequate fit $\left(R^{2}\right.$ between 0.028 and 0.291 ). PAL08 showed that it was not able to retrieve the bottom signal adequately in the studied area, since neither the in situ data-based models nor the image-based models for estimating SAV height provided satisfactory results with it. Further, the models based on $K_{d}^{P}(\beta 4, \beta 5, \beta 6, \beta 10, \beta 11$ and $\beta 12)$ did not yield an adequate fit (poor $\mathrm{R}^{2}$ and/or $p$-value), which indicated that the procedure used to calculate the $K_{d}^{P}$ may not be suitable for inland waters, since it was developed for coastal waters. Several models, while significant, produced poor correlations with $\mathrm{R}^{2}$ lower than 0.3. DIE03 derived $\beta 7$ and $\beta 9$ were selected as the best models based on $p$-value $(p<0.05)$ and $\mathrm{R}^{2}$. The $t$-test (significance level of $5 \%$ and degree of freedom, $\mathrm{n}=107$ ) was used for analyzing whether the difference between $\beta 7$ and $\beta 9$ is representative. The $t$-test proved that there were no significant statistical differences between these models. The RMSE $(0.29 \mathrm{~m})$ were the same for both models. Ultimately, $\beta 9$ was selected for implementation due to a slightly higher $\mathrm{R}^{2}$ (Fig. 11).

Four models exhibited significant $p$-value and $\mathrm{R}^{2}$ greater than 0.72 , based on the in situ data for SAV height estimates. DIE03 $\left(K_{d}\right.$ or $\left.K_{d}^{P}\right)$ was used in these models to retrieve the bottom, applying GRVI and G/R in the regression. The models based on the SPOT- 6 image presented satisfactory results only when DIE03 was used with $K_{d}$ (i.e., the use of $K_{d}{ }^{P}$ did not produce reasonable results). Both models based on in situ data and SPOT image obtained significant results when DIE03 was used with $K_{d}$, and the G/R and GRVI indices presented similar results. Even though Slope has been used successfully for detection of algal chl- $a$ concentration (Mishra and Mishra, 2010; Srichandan et al., 2015), all
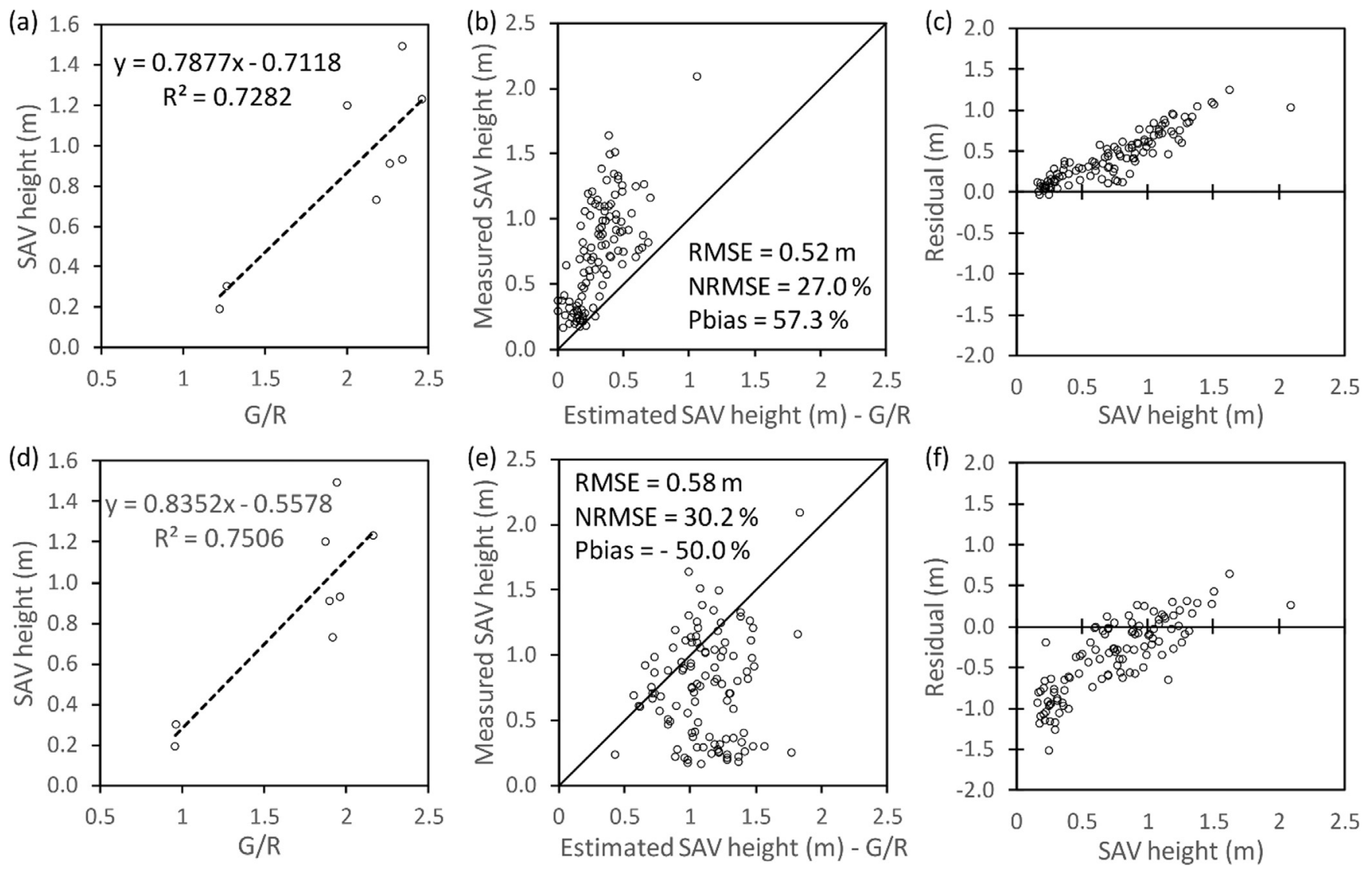

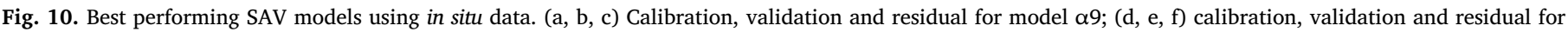
model $\alpha 12$. 
Table 2

SAV height model calibration $(\mathrm{n}=108)$ and validation $(\mathrm{n}=100)$ results using atmospherically corrected SPOT-6 $R_{r s-s}$ data.

\begin{tabular}{|c|c|c|c|c|c|c|c|}
\hline$R_{r s}^{b}$ or $R^{b}$ & Model & Equation & $\mathrm{R}^{2}$ & $p$-value & RMSE (m) & NRMSE (\%) & Pbias (\%) \\
\hline \multirow[t]{3}{*}{ PAL08 $\left(K_{d}\right)$} & $\beta 1$ & $\mathrm{SAV}=-1.0418(G R V I)+1.4631$ & 0.1673 & 0.000 & 0.38 & 20.0 & 2.1 \\
\hline & $\beta 2$ & SAV $=20187($ Slope $)+0.6554$ & 0.0724 & 0.005 & 0.40 & 20.6 & 4.0 \\
\hline & $\beta 3$ & $\mathrm{SAV}=-0.032(G / R)+1.0157$ & 0.291 & 0.000 & 0.34 & 17.6 & -0.1 \\
\hline \multirow[t]{3}{*}{ PAL08 $\left(\mathrm{K}_{\mathrm{d}}^{\mathrm{P}}\right)$} & $\beta 4$ & $\mathrm{SAV}=-1.0374(G R V I)+1.2243$ & 0.0885 & 0.002 & 0.39 & 20.1 & 1.5 \\
\hline & $\beta 5$ & $\mathrm{SAV}=2645.6($ Slope $)+0.625$ & 0.028 & 0.083 & - & - & - \\
\hline & $\beta 6$ & $\mathrm{SAV}=-0.1413(G / R)+1.1586$ & 0.1146 & 0.000 & 0.38 & 19.5 & 0.8 \\
\hline \multirow[t]{3}{*}{ DIE03 $\left(K_{d}, K_{L u}\right)$} & $\beta 7$ & $\mathrm{SAV}=3.157(G R V I)+0.2915$ & 0.5261 & 0.000 & 0.29 & 14.8 & 7.7 \\
\hline & $\beta 8$ & $\mathrm{SAV}=3480.9($ Slope $)+0.5658$ & 0.1529 & 0.000 & 0.37 & 19.0 & 4.9 \\
\hline & $\beta 9$ & $\mathrm{SAV}=1.2077(G / R)-0.8987$ & 0.5431 & 0.000 & 0.29 & 15.1 & 8.7 \\
\hline \multirow[t]{3}{*}{$\operatorname{DIE03}\left(\mathrm{K}_{\mathrm{d}}^{\mathrm{P}}, \mathrm{K}_{\mathrm{Lu}}\right)$} & $\beta 10$ & $\mathrm{SAV}=0.3291(G R V I)+0.6078$ & 0.0036 & 0.540 & - & - & - \\
\hline & $\beta 11$ & $\mathrm{SAV}=5270.9($ Slope $)+0.6228$ & 0.0954 & 0.001 & 0.38 & 19.9 & 4.76 \\
\hline & $\beta 12$ & $\mathrm{SAV}=0.0803(G / R)+0.5535$ & 0.005 & 0.468 & - & - & - \\
\hline
\end{tabular}
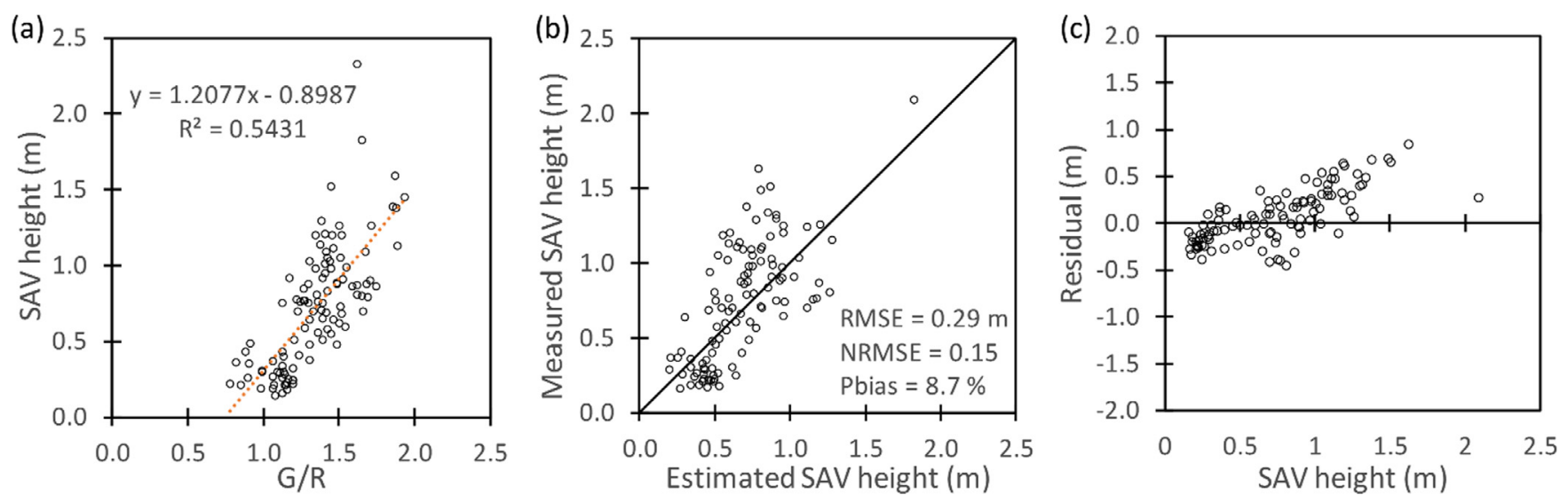

Fig. 11. Calibration (a) and validation (b) of DIE03 based $\beta 9$ using atmospherically corrected SPOT-6 image.

the models that used Slope, including in situ and image-based models, showed low $\mathrm{R}^{2}$.

Models calibrated using field data usually present satisfactory results because of the absence of atmospheric interference. However, in case of in situ SAV height models, the localized variations in $R_{r s_{s}}$ may have affected the fit of the model and increased the uncertainty. Although $R^{2}$ was greater than 0.7 , the validation was weak showing a large residual error (Fig. 10b and e). Both models presented similar RMSE, but the validation of model $\alpha 12$ was poorer, with a random spread (Fig. 10e). In addition, the residual of model $\alpha 12$ (Fig. 10f) was $-1.5 \mathrm{~m}$ for samples with low SAV height (up to $0.5 \mathrm{~m}$ ), so a strong overestimation at locations with low SAV height was observed; thereby model $\alpha 12$ was discarded from SAV height mapping. A slight increase in estimated SAV height was noted with the increase in measured SAV height when model $\alpha 9$ was applied (Fig. 10b), but an underestimation was evident. The residual of that model (Fig. 10c) presented values between 0 and $0.5 \mathrm{~m}$ for SAV heights up to $0.7 \mathrm{~m}$, which indicated a slight underestimation. As the SAV height increased, the residual of model $\alpha 9$ also increased. This suggests that the higher the measured $\mathrm{SAV}$, the higher the residual in model estimation (i.e., leading to an underestimation in SAV height values).

SPOT-6 calibrated models presented a suitable fit, where a clear tendency of the SAV height increasing was observed with increasing G/ $\mathrm{R}$ value (Fig. 11a). Even though the points were not all close to the 1:1 line (Fig. 11b), an appropriate adjustment was noted between the estimated and the measured SAV heights. Overall, a lower error was produced (NRMSE $=15.1 \%$ ) using the image in comparison with the model based on in situ data (NRMSE $=27.0 \%$ ). Residual values between -0.5 and +0.5 for model $\beta 9$ (Fig. 11c) were produced for SAV height up to $1 \mathrm{~m}$. In regions with SAV heights greater than $1 \mathrm{~m}$, the residual was between 0 and $1 \mathrm{~m}$ (underestimation); however, based on field data (echosounder), $<25 \%$ of samples showed SAV higher than $1 \mathrm{~m}$. Overall, SPOT-6 image-based model was comparatively more accurate in SAV height estimation than the in situ model. Some conditions may explain the differences between these models, such as the number of sample points, atmosphere interference, and environmental conditions on the day of data acquisition. Ghosh et al (2016) observed a similar phenomenon when comparing in situ reflectance-based VIs with MODIS derived VIs. They concluded that fine-scale spectral variabilities present in in situ reflectance data weaken the VIs' performance in predicting biophysical parameters, whereas, satellite data are influenced by a spatial averaging out effect which enhances the accuracy of VI based empirical models.

\subsubsection{SAV height map}

Both in situ data $(\alpha 9)$ and SPOT-6 ( $\beta 9)$ based models were used to estimate and map SAV height (Fig. 12a and b). The $\alpha 9$ model showed a pattern of underestimation in SAV heights (Fig. 10b). Consequently, the SAV height map generated from this model (Fig. 12a) presented low values. Most classes are below $1 \mathrm{~m}$, which did not match the SAV height measured in the field (echosounder). This fact was confirmed by the histogram of the image, with most values between 0.0 and $0.6 \mathrm{~m}$. The model calibrated with the image ( $\beta 9$ ) presented satisfactory results with RMSE lower than $0.3 \mathrm{~m}$. The predominance of SAV height was noted between 0.4 and $1.0 \mathrm{~m}$, which can be observed in both the thematic map and the histogram (Fig. 12b). In the highlighted inset, there is a region where the SAV height is greater than $1 \mathrm{~m}$, which was confirmed by the ground-based data. A higher transparency (lower $K_{\mathrm{d}}$ ) was noted in downstream regions (P20 for example), which can improve the SAV growth. The lower $K_{\mathrm{d}}$ is caused by the slow water flow due to the dam and greater depths that favor the deposition of suspended solids on the bottom. In upstream regions (P01 to P09), a lower SAV height was 

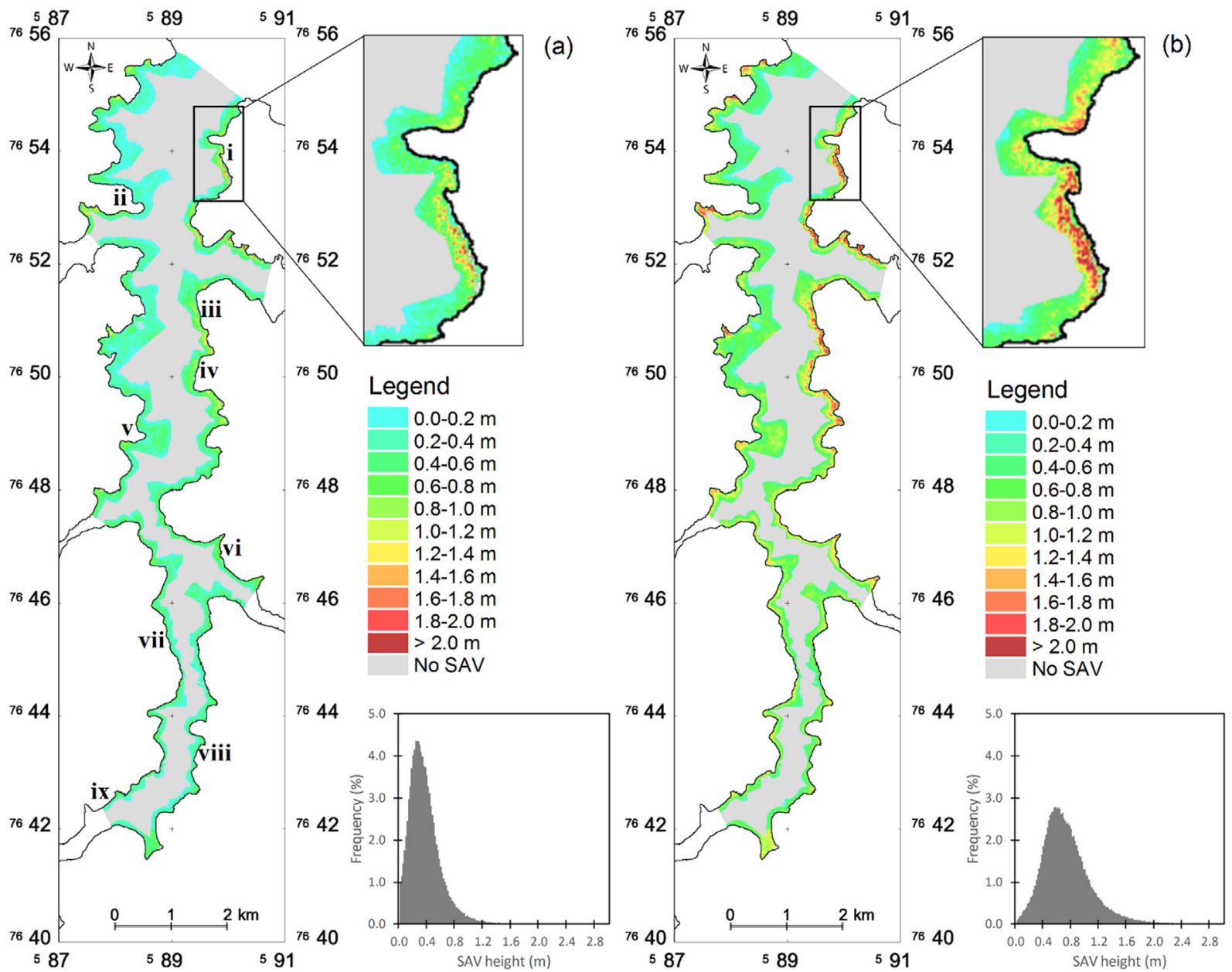

Fig. 12. SAV height map in the Bonito River based on models (a) $\alpha 9$ using in situ data and (b) $\beta 9$ using the atmospherically corrected SPOT-6 image. Regions indicated as i, ii, iii, iv, v, vi, vii, viii and ix are transects in which SAV height distribution was extracted for further analysis.

noted mainly because of the higher $K_{\mathrm{d}}$. Therefore, the SAV height distribution in the studied area corroborated with the SAV height distribution presented in the maps (Fig. 12) (i.e., taller SAV in downstream regions and lower SAV height in upstream regions).

The SAV height profiles (transect) based on field data acquired by the echosounder calculated using the in situ model and based on the SPOT-6 image model are shown in Fig. 13. These transects were acquired in nine regions distributed throughout the study area (i-ix in Fig. 12a and a-i in Fig. 13). A strong similarity was observed between the curves based on in situ data and those based on image data, that is, if an increase (or decrease) in SAV height based on the in situ model was noted, the same happened with the SAV height based on SPOT-6. In addition, the values of the SAV height calculated using image model were always higher than the values calculated from the in situ data model, which was expected, since both models used for SAV mapping were calibrated using the $G / R$ index and the bottom reflectance retrieved by DIE03 (with $K_{\mathrm{d}}$ ). The image-based model ( $\beta 9$ ) presented higher SAV height values than the in situ data-based model ( $\alpha 9)$. In general, a slight overestimation was observed in the $\beta 9$ model and an underestimation in the $\alpha 9$.

In the downstream regions, where taller SAVs were observed (Fig. 13a and b), there was difficulty in accurately estimating the SAV height greater than $1 \mathrm{~m}$. In upstream regions (Fig. 13g, h and i, for example), both $\alpha 9$ and $\beta 9$ models predicted SAV heights in good agreement with ground-truth. Therefore, based on adjusted models, the SAV height was estimated with higher accuracy in regions with shorter plants. Regions with SAV height lower than $1 \mathrm{~m}$ presented better estimation than regions with SAV height higher than $1 \mathrm{~m}$. In the middle of the reservoir (Fig. 13d-f), with SAV height between 0.2 and $1.2 \mathrm{~m}$, it was observed that the image-based model presented a behavior closer to ground-truth. Overall, the model based on the SPOT-6 image presented more accurate results.

\section{Conclusion}

This study presented a comprehensive methodology to generate SAV height distribution maps using both in situ and SPOT-6 satellite data. Only a handful of studies can be found on bottom reflectance derivation of benthic habitats using satellite data and none of the studies involve the use SPOT-6 data. Despite the difficulties in estimating SAV heights from inland waterbodies due to their optical complexities, the results provide useful initial evidence that it may be possible to use existing radiative transfer models to map them with adequate accuracy. The importance of accurate bottom reflectance retrieval for SAV height models has been emphasized in this study. Two widely used bottom reflectance models, proposed by Dierssen et al. (2003) and Palandro et al. (2008) were used with both SPOT-6 simulated in situ reflectance data and actual atmospherically corrected SPOT-6 data to derive bottom reflectance and develop SAV height models. This study also demonstrates the performance comparison of both models.

The model calibrated using in situ data presented a greater $R^{2}$, but with an underestimation of SAV height and high RMSE. This could either be due to the low number of sampling points $(n=8)$ used in calibration which may not be sufficient to build a robust prediction model or greater sensitivity of $R_{r s i}$ point data to localized variations in optically active constituents in water. Consequently, a greater number of 

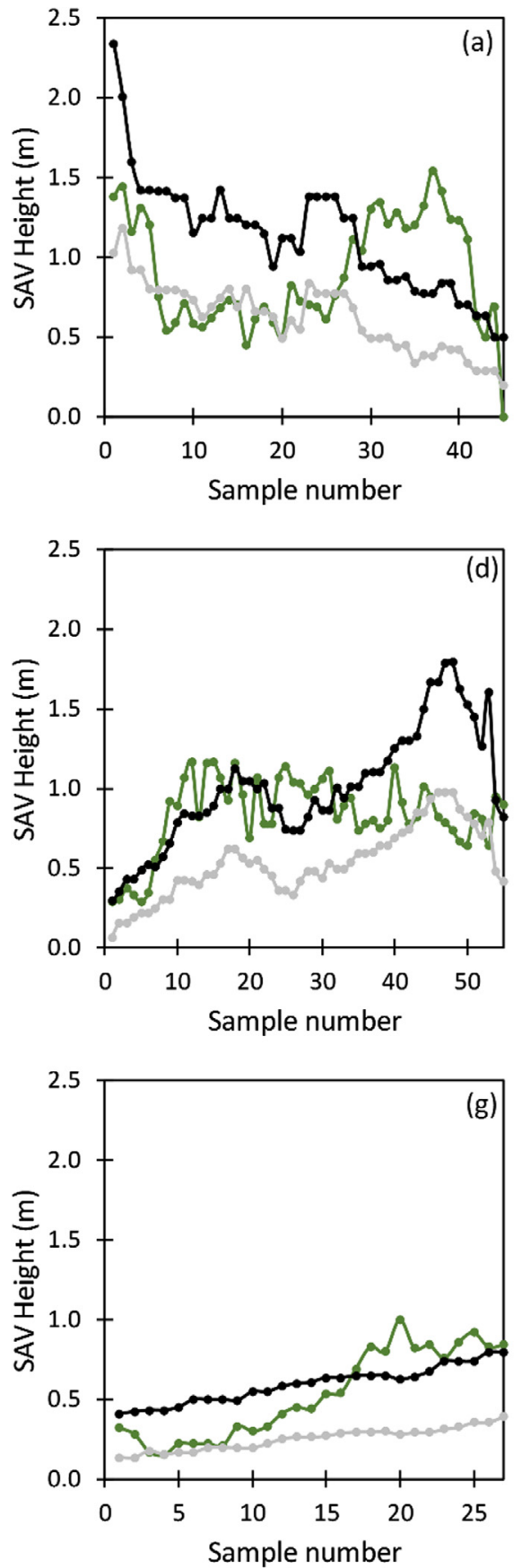
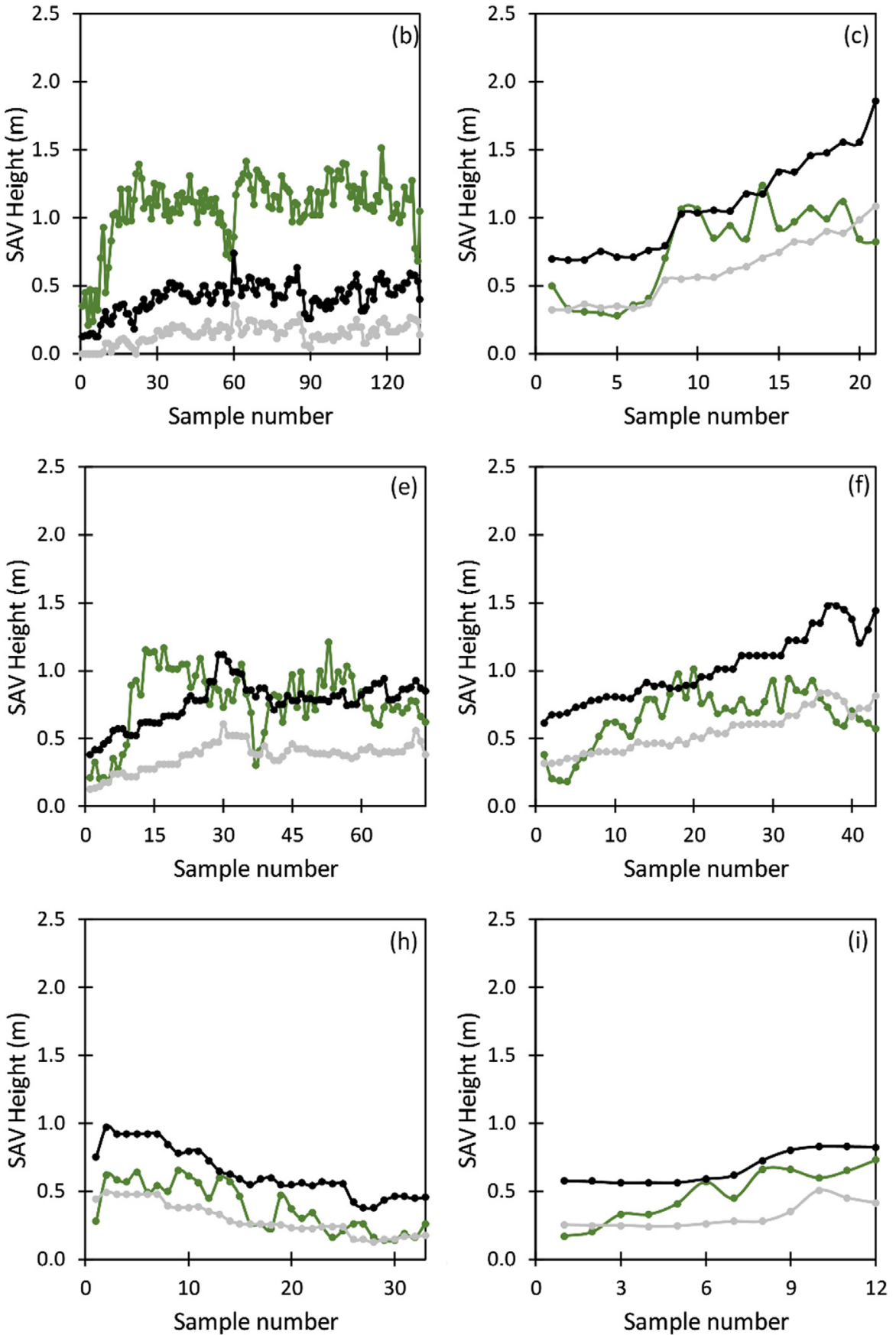

$\rightarrow$ Measured (Echosounder) $\rightarrow$ In situ data (model) $\rightarrow$ SPOT-6 Image (Model)

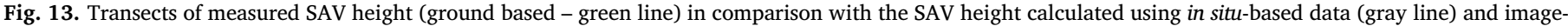
based (black line) models. (a), (b), (c), (d), (e), (f), (g), (h) and (i) represent the regions i, ii, iii, iv, v, vi, vii, viii and ix -indicated in Fig. 12a respectively.

sample points in calibration using in situ data is recommended for future research. Overall, the model based on the SPOT-6 image yielded more accurate results. Furthermore, regions with SAV lower than $1 \mathrm{~m}$ presented better estimation than regions with SAV higher than $1 \mathrm{~m}$. The finding is quite significant because the bottom signal detection is hampered by the water column even for shallow waterbodies, and the maximum depth of SAV occurrence in the study area is high (around $10 \mathrm{~m}$ ). Not many benthic reflectance studies have worked well in such deep waters. For example, Dogan et al. (2009) and Heblinski et al. (2011) showed SAV mapping with high accuracy, however, the maximum depth was about $3.5 \mathrm{~m}$. The SPOT- 6 based SAV model may have benefited from the average-out effect often experienced by satellite data compared to corresponding in situ optical data. Based on significant estimation of SAV height using a multispectral satellite sensor, SPOT-6, it is recommended to test the procedure using other sensors with different spectral and spatial resolutions. For future research, the use of per-pixel values of $K_{d}$ and $K_{L u}$ is suggested to retrieve the $R_{r s}{ }^{b}$ and $R^{b}$ in each region, since these values are different at each sampling point. The results could then be compared to the models developed in this study, where the average $K_{d}$ and $K_{L u}$ were used to estimate SAV height.

Inland waters including hydroelectric reservoirs face numerous problems due to the uncontrolled growth in SAV which is expected to 
increase in future because of nutrient pollution and climate change. Sonar surveys have been used to monitor SAV growth, but with high cost and time. Collecting SAV biomass samples in the field is quite challenging compared to SAV height which can be used to compute biomass instead. Using satellite-based models could be the only viable way, in terms of cost and temporal frequency, to perform periodic mapping of SAV height in inland waters which can significantly aid in ecosystem management. Although the initial results presented in this study are encouraging, the method needs to be further evaluated across different species, seasons, and turbidity regime, and at various other waterbodies to test its robustness and geographic scalability. Only then the proposed procedure can be used in other inland waters where part of the radiation reaching the bottom returns to the surface of the water, thus being detectable by remote sensing.

\section{Acknowledgments}

The authors wish to thank the São Paulo Research FoundationFAPESP (Projects number: 2012/19821-1 and 2013/09045-7) and the National Counsel of Technological and Scientific Development-CNPq (Projects numbers: 400881/2013-6, 472131/2012-5 and 482605/ 2013-8) for financial support and PNPD/CAPES for scholarship. Thanks to the University of Georgia (UGA) for facilitating collaboration between UNESP and UGA through the international student exchange program.

\section{References}

Adler-Golden, S.M., Matthew, M.W., Bernstein, L.S., Levine, R.Y., Berk, A., Richtsmeier, S.C., Acharya, P.K., Anderson, G.P., Felde, G., Gardner, J., Hike, M., Jeong, L.S., Pukall, B., Mello, J., Ratkowski, A., Burke, H.-H., 1999. Atmospheric correction for shortwave spectral imagery based on MODTRAN4. SPIE Proc. Imaging Spectrom. 3753, 61-69.

Armellina, A.D., Bezic, C.R., Gajardo, O.A., 1996. Propagation and mechanical control of Potamogeton illinoensis Morong in irrigation canals in Argentina. J. Aquat. Plant Manage. 34, 12-16.

Ashraf, S., Brabyn, L., Hicks, B.J., Collier, K., 2010. Satellite remote sensing for mapping vegetation in new zealand freshwater environments: a review. New Zealand Geogr. $66,33-43$.

Astrium, 2013. Spot 6 \& Spot 7 Imagery - User Guide. Si/Dc/13034-V1.0.

Batista, L.F.A., Imai, N.N., Rotta, L.H.S., Watanabe, F.S.Y., Velini, E.D., 2012. Analysis of the spatial-temporal dynamics of submerged macrophytes mapped with hydroacoustic techniques in taquaruçu reservoir. Paranapanema River. Planta Daninha 30 (2), 241-252.

Biosonics, 2004a. User Guide: Visual Acquisition 5.0, Seattle: Biosonics Inc. p. 60.

Biosonics. "Calibration of BioSonics Digital Scientific Echosounder Using T/C Calibration Spheres.”. Seattle: Biosonics Inc., 2004b. Accessed 18 January 2016. < http://www. biosonicsinc.com/doc_library/docs/DTXcalibration2e.pdf $>$.

Biosonics, 2008. User Guide: EcoSAV 1. Seattle: BioSonics Inc. p. 48p.

Boschi, L.S., 2011. Espacialização do biovolume de plantas aquáticas submersas a partir da integração de dados obtidos por sensores remotos. $162 \mathrm{f}$. Tese (Doutorado em Ciências Cartográficas) - Faculdade de Ciências e Tecnologia, Universidade Estadual Paulista, Presidente Prudente.

Brando, V.E., Anstee, J.M., Wettle, M., Dekker, A.G., Phinn, S.R., Roelfsema, C., 2009. A physics based retrieval and quality assessment of bathymetry from suboptimal hyperspectral data. Remote Sens. Environ. 113 (4), 755-770.

Carpenter, S.R., Lodge, D.M., 1986. Effects of submersed macrophytes on ecosystem processes. Aquatic Botany 26, 341-370.

Chamberlain, R.H., Doering, P.H., Orlando, B., Sabol, B.M., 2009. Comparison of manual and hydroacoustic measurement of seagrass distribution in the Caloosahatchee Estuary, Florida. Biol. Sci. - Florida Scient. 72 (4), 386-405.

Chen, J.M., Cihlar, J., 1996. Retrieving leaf area index of boreal conifer forests using Landsat TM images. Remote Sens. Environ. 55 (2), 153-162.

Chilton, E.W., Muoneke, M.I., 1992. Biology and management of grass carp (Ctenopharyngodon idella, Cypfinidae) for vegetation control: a North American perspective. Rev. Fish Biol. Fish. 2, 283-320.

Dall'olmo, G., Gitelson, A.A., 2005. Effect of bio-optical parameter variability on the remote estimation of chlorophyll-a concentration in turbid productive waters: experimental results. Appl. Opt. 44 (3), 412-422.

Dekker, A.G., Brando, V.E., Anstee, J.M., 2005. Retrospective seagrass change detection in a shallow coastal tidal Australian lake. Remote Sens. Environ. 97, 415-433.

Dierssen, H.M., Zimmerman, R.C., Leathers, R.A., Downes, T.V., Davis, C.O., 2003. Ocean color remote sensing of seagrass and bathymetry in the Bahamas Banks by highresolution airborne imagery. Limnol. Oceanogr. 48 (1part2), 444-455.

Dogan, O.K., Akyurek, Z., Beklioglu, M., 2009. Identification and mapping of submerged plants in a shallow lake using quickbird satellite data. J. Environ. Manage. 90 2138-2143.
Engel, S., 1990. Ecosystem Responses to Growth and Control of Submerged Macrophytes: A Literature Review. Technical Bulletin No. 170. Department of Natural Resources, Madison, Wisconsin.

Falkowski, M.J., Gessler, P.E., Morgan, P., Hudak, A.T., Smith, A.M.S., 2005. Characterizing and mapping forest fire fuels using ASTER imagery and gradient modeling. Forest Ecol. Manage. 217, 129-146.

Ghosh, S., Mishra, D.R., Gitelson, A., 2016. Long-term monitoring of biophysical characteristics of tidal wetlands in the northern Gulf of Mexico-a methodological ap proach using MODIS. Remote Sens. Environ. 173, 39-58.

Giardino, C., Bresciani, M., Valentini, E., Gasperini, L., Bolpagni, R., Brando, V.E., 2015. Airborne hyperspectral data to assess suspended particulate matter and aquatic vegetation in a shallow and turbid lake. Remote Sens. Environ. 157, 48-57.

Gitelson, A.A., Dall'olmo, G., Moses, W., Rundquist, D.C., Barrow, T., Fisher, T.R., Gurlin, D., Holz, J., 2008. A simple semi-analytical model for remote estimation of chlorophyll-A in turbid waters: validation. Remote Sens. Environ. 112, 3582-3593.

Hanlon, S.G., Hoyer, M.V., Cichra, C.E., Canfield Jr., D.E., 2000. Evaluation of macrophyte control in 38 Florida lakes using triploid grass carp. J. Aquat. Plant Manage. $38,48-54$

Heblinski, J., Schmieder, K., Heege, T., Agyemang, T.K., Sayadyan, H., Vardanyan, L., 2011. High-resolution satellite remote sensing of littoral vegetation of Lake Sevan (Armenia) as a basis for monitoring and assessment. Hydrobiologia 661, 97-111.

Hunt Jr., E.R., Cavigelli, M., Daughtry, C.S.T., McMurtrey III, J., Walthall, C.L., 2005 Evaluation of digital photography from model aircraft for remote sensing of crop biomass and nitrogen status. Precision Agric. 6, 359-378.

Hunter, P.D., Gilvear, A.N., Willby, N.J., Kelly, A., 2010. Mapping macrophytic vegetation in shallow lakes using the Compact Airborne Spectrographic Imager (CASI). Aquatic Conserv: Mar. Freshw. Ecosyst. 20, 717-727.

ITT Visual Information Solutions. ENVI. Atmospheric Correction Module: QUAC and FLAASH User's Guide, 2009.

Jakubauskas, M.E., Peterson, D. L., Campbell, S.W., de Noyelles Jr., F., Campbell, S.D., Penny, D., 2002. Mapping and Monitoring Invasive Aquatic Plant Obstructions in Navigable Waterways Using Satellite Multispectral Imagery. In: Pecora 15/Land Satellite Information IV/ISPRS Commission I/FIEOS 2002 Conference Proceedings, edited by S. Morain and A. Budge, Denver, CO.

Jensen, J.R., 2009. Remote Sensing of the Environment: An Earth Resource Perspective. Translated by Epiphanio (Coord.), "Sensoriamento remoto do ambiente - uma perspectiva em recursos terrestres". São José dos. Parêntese, Campos, SP.

Jordan, C.F., 1969. Derivation of leaf-area index from quality of light on the forest floor Ecology 50 (4), 663-666.

Kirk, J.T.O., 2011. Light and Photosynthesis in Aquatic Ecosystems, third ed. Cambridge University Press, New York.

Lee, Z.P., Carder, K.L., 2002. Effect of spectral band numbers on the retrieval of water column and bottom properties from ocean color data. Appl. Opt. 41 (12), 2191-2201.

Lee, Z.P., Carder, K.L., Hawes, S.K., Steward, R.G., Peacock, T.G., Davis, C.O., 1994. Model for the interpretation of hyperspectral remote-sensing reflectance. Appl. Opt 33 (24), 5721-5732.

Malthus, T., 2017. Bio-optical modeling and remote sensing of aquatic macrophytes. In: Mishra, D.R., Ogashawara, I., Gitelson, A. (Eds.), Bio-optical Modeling and Remote Sensing of Inland Waters. Elsevier, pp. 263-308.

Marcondes, D.A.S., Mustafá, A.L., Tanaka, R.H., 2003. In: "Estudos para Manejo Integrado de Plantas Aquáticas no Reservatório de Jupiá". Chap 15 in Ecologia e Manejo de Macrófitas Aquáticas. EDUEM, Maringá, pp. 299-317.

Maritorena, S., Morel, A., Gentili, B., 1994. Diffuse reflectance of oceanic shallow waters: Influence of water depth and bottom albedo. Limnol. Oceanogr. 39 (7), 1689-1703.

Mishra, D.R., Mishra, S., 2010. Plume and bloom: effect of the Mississippi River diversion on the water quality of Lake Pontchartrain. Geocarto Int. 25 (7), 555-568.

Mishra, D.R., Narumalani, S., Rundquist, D., Lawson, M., 2005. Charactering the vertical diffuse attenuation coefficient for downwelling irradiance in coastal waters: implications for water penetration by high resolution satellite data. ISPRS J. Photogram. Remote Sens. 60, 48-64.

Mishra, D.R., Narumalani, S., Rundquist, D., Lawson, M., 2006. Benthic habitat mapping in tropical marine environments using QuickBird multispectral data. Photogram. Eng. Remote Sens. 72 (9), 1037-1048.

Mishra, D.R., Narumalani, S., Rundquist, D., Lawson, M., Perk, R., 2007. Enhancing the detection and classification of coral reef and associated benthic habitats: a hyperspectral remote sensing approach. J. Geophys. Res. 112 (C08014), 1-18.

Mishra, D.R., Cho, H.J., Ghosh, S., Downs, S., Fox, A., Merani, P.B.T., Kirui, P., Jackson, N., Mishra, S., 2012. Post-spill state of the marsh: remote estimation of the ecological impact of the Gulf of Mexico oil spill on Louisiana salt marshes. Remote Sens. Environ. 118, 176-185.

Mobley, C.D., 1994. Light and Water: Radiative Transfer in Natural Waters. Academic Press, San Diego, pp. 592.

Motohka, T., Nasahara, K.N., Oguma, H., Tsuchida, S., 2010. Applicability of green-red vegetation index for remote sensing of vegetation phenology. Remote Sens. 2, 2369-2387.

Mueller, J.L., 2003. In-water radiometric profile measurements and data analysis protocols. In: Mueller, J.L., Fargion, G.S., Mcclain, C.R. (Eds.), Ocean Optics Protocols for Satellite Ocean Color Sensor Validation. NASA, Goddard Space Flight Space Center, Greenbelt, Maryland 20771, Revision 4, Volume Iii.

Palandro, D.A., Andréfouët, S., Hu, C., Hallock, P., Müller-Karger, F., Dustan, P., Callahan, M.K., Kranenburg, C., Beaver, C.R., 2008. Quantification of two decades of shallow-water coral reef habitat decline in the Florida keys national marine sanctuary using landsat data (1984-2002). Remote Sens. Environ. 112, 3388-3399.

Pande-Chhetri, R., Abd-Elrahman, A., Jacoby, C., 2014. Classification of submerged aquatic vegetation in black river using hyperspectral image analysis. Geomatica 68 (3), 169-182. 
Pope, R.M., Fry, E.S., 1997. Absorption spectrum (380-700 nm) of pure water II. Integrating cavity measurements. Appl. Opt. 36 (33), 8710-8723.

Rockwell, H.W., 2003. Summary of a survey of the literature on the economic impact of aquatic weeds. In: The economic impact of aquatic weeds. Report for the Aquatic Ecosystem Restoration Foundation. Accessed 12 August 2015.

Roelfsema, C.M., Lyons, M., Kovacs, E.M., Maxwell, P., Saunders, M.I., Samper-Villarreal, J., Phinn, S.R., 2014. Multi-temporal mapping of seagrass cover, species and biomass: a semi-automated object based image analysis approach. Remote Sens. Environ. 150, 172-187.

Rotta, L.H.S., Imai, N.N., Batista, L.F.A., Boschi, L.S., Galo, M.L.B.T., Velini, E.D., 2012. Hydro-acoustic remote sensing in submerged aquatic macrophyte mapping. Planta Daninha 30 (2), 229-239.

Rotta, L.H.S., Imai, N.N., Boschi, L.S., 2013. Imagem de Alta Resolução Espacial na Detecção de Macrófitas Submersas - Estudo de Caso. Revista Brasileira de Cartografia 65 (1), 95-109.

Rotta, L.H.S., Mishra, D.R., Alcântara, E.H., Imai, N.N., 2016. Analyzing the status of submerged aquatic vegetation using novel optical parameters. Int. J. Remote Sens. Remote 37 (16), 3786-3810.

Rundquist, D.C., Han, L., Schalles, J.F., Peake, J.S., 1996. Remote measurement of algal chlorophyll in surface water: the case for the first derivative of reflectance near 690 nm. Photogrammetric Eng. Remote Sens. 62 (2), 195-200.

Sabol, B.M., Melton, R.E., Chamberlan, R., Doering, P., Haunert, K., 2002. Evaluation of a digital echo sounder system for detection of submersed aquatic vegetation. Estuaries $25,133-141$.

Schmidt, J.C., 2009. An overview of chemicals for aquatic plant control. Lake and Reservoir Management 1 (1), 453-455.

Srichandan, S., Maharana, B., Kim, J.Y., Kumar, A., Mishra, D.R., Bhadury, P., Muduli, P., Pattnaik, A.K., Rastogi, G., 2015. Interannual and cyclone-driven variability in phytoplankton communities of a tropical coastal lagoon. Mar. Pollut. Bull. 101 (1), $39-52$

Thomaz, S.M., Esteves, F.A., Murphy, K.J., Dos-Santas, A.M., Caliman, A., Guariento, R.D., 2008. Aquatic macrophytes in the tropics: ecology of population and communities, impact of invasion and use by man. Tropical Biol. Conserv. Manage. 4, 33-37.

Tucker, C.J., 1979. Red and photographic infrared linear combinations for monitoring vegetation. Remote Sens. Environ. 8, 127-150.

Velini, E.D., Corrêa, M.R., Tanaka, R.H., Bravin, L.F., Antuniassi, U.R., Carvalho, F.T., Galo, M.L.B.T., 2005. Operational evaluation of mechanical control of aquatic macrophytes submerged in the Jupia reservoir. Planta Daninha, Viçosa-MG 23 (2), 277-285.

Visser, F., Buis, K., Verschoren, V., Meire, P., 2015. Depth estimation of submerged aquatic vegetation in clear water streams using low-altitude optical. Remote Sens. Sensors 15, 25287-25312.

Watanabe, F.S.Y., Imai, N.N., Alcântara, E.H., Rotta, L.H.S., Utsumi, A.G., 2013. Signal classification of submerged aquatic vegetation based on the hemispherical-conical reflectance factor spectrum shape in the yellow and red regions. Remote Sens. 5, 1856-1874.

Wells, R.D.S., Bannon, H.J., Hicks, B.J., 2003. Control of macrophytes by grass carp (Ctenopharyngodon idella) in a Waikato drain, New Zealand. New Zealand J. Mar. Freshwater Res. 37 (1), 85-93.

Wetzel, R.G., 2001. Limnology: Lake and River Ecosystems, third ed. Academic press, San Diego.

Williams, D.J., Rybicki, N.B., Lombana, A.V., O’brien, T.M., Gomez, R.B., 2003. Preliminary investigation of submerged aquatic vegetation mapping using hyperspectral remote sensing. Environ. Monit. Assess. 81, 383-392.

Zou, W., Yuan, L., Zhang, L., 2013. Analyzing the spectral response of submerged aquatic vegetation in a eutrophic lake, Shanghai, China. Ecol. Eng. 57, 65-71. 